Federal Reserve Bank of Dallas

Globalization and Monetary Policy Institute

Working Paper No. 87

http://www.dallasfed.org/assets/documents/institute/wpapers/2011/0087.pdf

\title{
Currency Blocs in the 21st Century ${ }^{*}$
}

\author{
Christoph Fischer \\ Deutsche Bundesbank
}

July 2011

\begin{abstract}
Based on a classification of countries and territories according to their regime and anchor currency choice, the study considers the two major currency blocs of the present world. A nested logit regression suggests that long-term structural economic variables determine a given country's currency bloc affiliation. The dollar bloc differs from the euro bloc in that there exists a group of countries that peg temporarily to the US dollar without having close economic affinities with the bloc. The estimated parameters are consistent with an additive random utility model interpretation. A currency bloc equilibrium in the spirit of Alesina and Barro (2002) is derived empirically.
\end{abstract}

JEL codes: F02, F31, F33, E42, C25

\footnotetext{
* Christoph Fischer, Deutsche Bundesbank, Wilhelm-Epstein-Str.14, 60431 Frankfurt, Germany. +49-69-9566-2304. christoph.fischer@bundesbank.de. I would like to thank Stefan Gerlach, Ulrich Grosch, Heinz Herrmann, Mathias Hoffmann, Akito Matsumoto, Andy Rose and Mark Spiegel for their valuable suggestions and comments. All remaining errors are my own. The views in this paper are those of the author and do not necessarily reflect the views of the Deutsche Bundesbank, the Federal Reserve Bank of Dallas or the Federal Reserve System.
} 


\title{
Currency Blocs in the $21^{\text {st }}$ Century
}

\author{
"Perhaps the most underrated determinant and measure \\ of international currency status ... is the 'anchor currency' (peg) function."
}

Papaioannou and Portes (2010)

\section{Introduction}

In recent years, economists and politicians have started to discuss whether another currency will one day be able to rival the dominant international role of the US dollar. Portes and Rey (1998) were among the first to predict that the dollar would "face stiff competition” once the euro was created. More recently, Eichengreen (2011) expects a system of multiple international currencies, in which "the dollar, the euro, and the renminbi will be the leading international currencies” (p 151). Chinn and Frankel (2007, 2008) estimate that the euro may surpass the dollar as the leading reserve currency in a few years. Focusing more on their role as anchor currencies, Posen $(2008,2009)$ doubts that the euro will be able to attain a status comparable to that of the US dollar.

Turning from the future to the present, the current world economy is shaped by two major currency blocs which coexist with numerous floating currencies. The present study analyses this state of the world along three sets of questions: (1) What are the characteristics of the present currency blocs? (2) How do long-term structural variables affect an economy's anchor currency choice? Which distinctive features of the US dollar bloc and the euro bloc can be inferred from the analysis? (3) What might a currency bloc equilibrium based on the above analysis be like? How would currently discussed currency regime-related policy decisions affect this equilibrium?

The first part of the paper deals with question (1). All the countries and territories of the world are classified according to their exchange rate regime and anchor currency choice. The classification is used to give a precise overview of the current extensiveness of the two major currency blocs.

In a second step, the influence of long-term structural economic variables on exchange rate regime and anchor currency choice is estimated. This part of the analysis relates to the empirical optimum currency area (OCA) literature surveyed, for instance, by Klein and Shambaugh (2010) and von Hagen and Zhou (2007). Most earlier studies, however, differ from the present one in that they usually focus on currency regime 
choices, do not distinguish between different anchor currencies, and, therefore, say nothing about the determinants of currency bloc affiliation. In this literature, anchor currency choice has attracted surprisingly little attention. As an exception, Meissner and Oomes (2009) explicitly consider anchor currency choice but their sample ends in 1998, the year before the euro was introduced. Since then, the situation has changed fundamentally because, now, there are two major currency blocs instead of just one. A further contribution made by this part of the paper is methodological: The anchor currency choice options are conditional on a decision on an exchange rate peg in the first place. This obvious nesting structure of the modelled decision suggests using a nested logit approach for estimation. The approach allows us to isolate factors that distinguish countries which peg to the US dollar from euro bloc countries.

Estimation results show that OCA criteria and related structural variables are significant determinants of countries' currency regime and anchor currency choices. Moreover, the estimated model is found to be consistent with an additive random utility model (ARUM) interpretation. This implies that countries choose the regime that provides the highest utility, while the utility functions depend additively on the explanatory variables. For a few countries, however, the estimated high utility of the chosen regime is due to a large error term, and the structural explanatory variables may suggest that a change in the currency regime significantly increases their estimated utility.

The consequences of this result are explored further in part three of the study. Adopting an equilibrium definition from Alesina and Barro (2002), a currency bloc equilibrium is derived empirically. Similar to Alesina et al (2002), the estimated optimal currency regime and anchor currency choice is determined for each country. The present study goes beyond Alesina et al (2002), however, in that the optimal anchor currency choice is derived from estimated utilities that, in turn, reflect the total influence of all currency regime determinants. The computed currency bloc equilibrium is subsequently used as a baseline scenario for an analysis of the effects of a number of economic policy decisions. The policy shocks include the adoption of a euro peg by some European Union countries which currently allow their currencies to float vis-à-vis the euro, and the termination of the use of the US dollar as an invoice currency for oil 
exports. A final exercise assesses the renminbi's potential for becoming the core of a third currency bloc.

The next chapter deals with classification issues and includes a description of the two currency blocs. Chapter 3 details the econometric approach. Chapter 4 explains the explanatory variables used in the estimation, the results of which are presented in chapter 5. Currency bloc equilibria are computed and discussed in Chapter 6, which also includes counterfactual analyses of policy decisions. Chapter 7 concludes.

\section{Currency blocs since the introduction of the euro - a descriptive overview}

\subsection{Currency regime classification}

For an investigation of currency blocs, it is important to define carefully the limits of each bloc. This basically amounts to choosing a suitable exchange rate classification scheme. Since the study aims to explain the present pattern of currency bloc composition and to provide an outlook for the near future, the classification scheme needs to be up to date. In order to be representative, the scheme needs, further, to include all the countries in the world. Since the authorities' declarations may differ from their real intentions or economic necessities, as is reported, for example, by Calvo and Reinhart (2002), a de facto classification is appropriate. However, the authorities' effective decisions should play a role, since they are modelled as being a reaction to the structure of their countries' economy.

A classification scheme that fulfils the above requirements to a large degree is the IMF's de facto classification of exchange rate arrangements. ${ }^{1}$ Starting with the 1999 volume, the IMF's “Annual Report on Exchange Arrangements and Exchange Restrictions" contains information on de facto exchange rate regimes rather than de jure exchange rate regimes, as published earlier. As outlined in the compilation guide chapter of these reports, countries are required to notify their exchange rate regime to the IMF. If this de jure regime is empirically confirmed over at least six months, the de jure classification is adopted in the de facto classification; otherwise, the regime is reclassified according to the empirical results. Concerning anchor currency choice, the

\footnotetext{
${ }^{1}$ Apart from the IMF's exchange rate classification scheme, alternative schemes have been developed, notably by Levy-Yeyati and Sturzenegger (2003), Reinhart and Rogoff (2004), Shambaugh (2004), and, more recently, Dubas, Lee and Mark (2010).
} 
IMF approach's inherent check of whether the officially proclaimed or unofficially notified de jure exchange rate regime has been applied de facto is advantageous because, otherwise, it may be hard to identify, in particular, currency baskets that are used as anchors.

Since the primary objective of the study is an investigation into currency bloc composition, the classification of exchange rate regimes has been confined just to the two coarse categories "peg" and "float" without further specifying the type of the regime. Borderline cases such as crawling pegs, crawling bands ${ }^{2}$ or regimes of the IMF's residual category "other managed arrangements" have been assigned to the category of floating exchange rates in order not to contaminate the modelling of the anchor currency decision and because, in such cases, it is unclear whether the authorities are really willing to bind their own monetary policy to the anchor country authorities' decisions. Because of the present dominance of the US dollar and the euro as anchor currencies, all the remaining pegs, including those to currency baskets, have been combined in the residual category "peg to another currency". This leaves a classification into the four categories: floating exchange rate, peg to the US dollar, peg to the euro, and peg to some other currency.

The IMF's data have been complemented by information taken from the Deutsche Bundesbank’s monthly publication “Exchange Rate Statistics, Statistical Supplement to the Monthly Report 5”. The Table in Appendix 1 displays the resulting classification for each country and territory in the world since 1999. The observation period has been chosen to start in 1999 because this was the year in which the euro, the core currency of the euro bloc, was introduced and when popular discussions on an end to the "unipolar" global exchange rate system centred around the US dollar gradually began to emerge.

\subsection{The two major currency blocs in $\mathbf{2 0 0 8}$}

The Table in Appendix 1 reveals that only 26 out of 229 countries and territories chose a peg to a currency basket or to a currency other than the US dollar or the euro in 2008. While the countries that peg to a currency basket include some middle-income

\footnotetext{
${ }^{2}$ As an example, consider the Chinese renminbi during the episode of gradual appreciation vis-à-vis the US dollar in 2006 and 2007, which might be classified as crawling peg or band.
} 
countries, notably Libya, Morocco and Syria, the large majority of the countries in this category are small countries, microstates or dependent territories.

In contrast, the US dollar bloc and the euro bloc each comprised 56 countries and territories in 2008. ${ }^{3}$ The maps in Figures 1 to 3 show the geographic distribution of countries and territories belonging to either of the two major currency blocs in this year. US dollar bloc members are displayed in green and euro bloc members in blue. The maps show that, apart from the USA, the US dollar bloc comprises, first, many smaller countries and territories of Central America, the West Indies and the northern part of South America; second, there is a cluster of mostly oil-exporting countries in the Arabian peninsula and Central Asia; third, some present and former tiny dependencies of the USA in the Pacific also belong to the US dollar bloc; and fourth, a small group of other countries limits the flexibility of their currencies vis-à-vis the US dollar. Some of them, like Angola or Ecuador, are oil exporters; others are very small, but the most important of all dollar peggers in economic terms, China, also belongs to this group.

It may be instructive to note that, apart from China (including Hong Kong and Macao), none of the East and Southeast Asian emerging markets peg their currencies to the US dollar. Foreign exchange market interventions to smooth fluctuations vis-à-vis the dollar are, however, widespread among these countries. ${ }^{4}$ Moreover, there is no longer any European country that limits the flexibility of its currency against the US dollar. Most recently, Belarus and the Ukraine abandoned their dollar pegs during the financial crisis. Apart from some oil exporters, finally, there is hardly any country in South America or Africa that belongs to the US dollar bloc in 2008.

The euro bloc is obviously concentrated on Europe and includes, naturally enough, European Monetary Union members, countries that participate in the Exchange Rate Mechanism II, some Balkan countries and European microstates. A second group of euro bloc members are former and current French, Portuguese, Spanish and Danish dependent territories, mainly in Africa.

\footnotetext{
${ }^{3}$ Eichengreen (2011, p 125) reports a relation of " 54 countries pegged to the U.S. dollar, compared to just 27 to the euro", but he will certainly have ignored, inter alia, the euro area countries in his count.

${ }^{4}$ Cobham (2008) finds, accordingly, for 1999-2007 that the currencies of several of these countries, while not being pegged to the dollar, are relatively more aligned to the US dollar than to the euro.
} 
While the number of countries and territories in the US dollar and the euro currency blocs is the same, the US dollar bloc is larger when measured in economic terms; expressed in 2005 constant purchasing power parity units as provided by the World Bank, the combined GDP of the US dollar bloc was 189\% of the corresponding euro bloc value in 1999 and 209\% in 2008. These figures need, of course, to take into account the fact that, unlike the euro bloc, the US dollar bloc is dominated by two economies, the USA and China, which together make up between 83\% of the US dollar bloc's GDP in 1999 and 90\% in 2008. In 2006 and 2007, when the authorities in China were pursuing an appreciation policy against the US dollar and China was classified as having a floating exchange rate regime, the combined US dollar bloc's GDP consequently fell to $160 \%$ and $150 \%$ of the euro bloc's value, respectively.

The Table in Appendix 1 allows us to take a closer look at the evolution of the two major currency blocs in the decade prior to 2008. It turns out that the euro bloc was extremely stable compared with the US dollar bloc. The only countries that left the euro bloc between 1999 and 2008 were Hungary and Croatia. In contrast, 33 countries from all over the world left the US dollar bloc at least once during this period. The large number of exits from a dollar peg, however, does not imply that there was a decline in the number of countries limiting the flexibility of their currency vis-à-vis the US dollar; instead, the number of dollar bloc countries and territories even increased slightly compared with 1999.

\section{Econometric approach}

Given the classification into the four categories described in the previous chapter, the consideration of whether to join (or leave) a currency bloc needs to be taken within a framework as shown in Figure 4. This involves two interrelated issues: First, the decision on a specific currency regime and, second, given that a peg has been chosen, the decision on a specific anchor currency. The issue of anchor currency choice arises only conditional on a decision on a limit to exchange rate flexibility.

A proper estimation method for cases where decisions have a clear nesting structure, like the one in Figure 4, is the nested logit, which goes back to McFadden (1978, 1981). It differs from a simple multinomial logit in that, here, the multinomial logit's assumption of independence of irrelevant alternatives is relaxed. While a 
multinomial logit would treat the residuals of the random utility from all the four alternatives as being independent of each other, the nested logit allows them to be correlated.

Assume that all the regressors vary across countries but not across alternatives and that a flexible exchange rate (alternative 4) is the base category for currency regime choice, the first-level decision. Denote the probabilities $p$ of country $i(i=1, \ldots, N)$ choosing a pegged $(P)$ or a floating $(F)$ exchange rate as $p_{i P}$ and $p_{i F}=1-p_{i P}$, respectively. Assume, further, that the option to choose an anchor currency other than the US dollar or the euro is the base category for anchor currency choice, the secondlevel decision. Given that country $i$ decides to peg its exchange rate, denote the probabilities of choosing the euro as anchor currency (alternative 1), the US dollar (alternative 2), or some other currency (alternative 3), as $p_{i 1 \mid P}, p_{i 2 \mid P}$, and $p_{i 3 \mid P}=1-p_{i 1 \mid P}-p_{i 2 \mid P}$. Then, the overall probabilities of country $i$ choosing one of the four options are given in a nested logit framework by

$$
\begin{gathered}
p_{i, \text { peg_euro }}=p_{i 1}=p_{i P} \times p_{i|| P}=\frac{\exp \left(\mathbf{z}^{\prime} \boldsymbol{\alpha}+\tau \cdot I\right)}{1+\exp \left(\mathbf{z}^{\prime} \boldsymbol{\alpha}+\tau \cdot I\right)} \cdot \frac{\exp \left(\mathbf{x}_{\mathbf{1}}^{\prime} \boldsymbol{\beta}_{\mathbf{1}} / \tau\right)}{\exp (I)}, \\
p_{i, \text { peg_dollar }}=p_{i 2}=p_{i P} \times p_{i 2 \mid P}=\frac{\exp \left(\mathbf{z}^{\prime} \boldsymbol{\alpha}+\tau \cdot I\right)}{1+\exp \left(\mathbf{z}^{\prime} \boldsymbol{\alpha}+\tau \cdot I\right)} \cdot \frac{\exp \left(\mathbf{x}_{\mathbf{2}}^{\prime} \boldsymbol{\beta}_{\mathbf{2}} / \tau\right)}{\exp (I)}, \\
p_{i, \text { peg_other }}=p_{i 3}=p_{i P} \times p_{i 3 \mid P}=\frac{\exp \left(\mathbf{z}^{\prime} \boldsymbol{\alpha}+\tau \cdot I\right)}{1+\exp \left(\mathbf{z}^{\prime} \boldsymbol{\alpha}+\tau \cdot I\right)} \cdot \frac{1}{\exp (I)},
\end{gathered}
$$

and

$$
p_{i, f l o a t}=p_{i 4}=p_{i F}=\frac{1}{1+\exp \left(\mathbf{z}^{\prime} \boldsymbol{\alpha}+\tau \cdot I\right)}
$$

where $\sum_{j=1}^{4} p_{i j}=1$ for each $i, \mathbf{z}$ is a vector of explanatory variables for the first-level decision, currency regime choice, $\alpha$ is the corresponding parameter vector, $\mathbf{x}_{\mathbf{1}}$ and $\mathbf{x}_{\mathbf{2}}$ are two vectors of explanatory variables for the second-level decision, anchor currency choice, $\mathbf{x}_{1}\left(\mathbf{x}_{2}\right)$ determining the choice of a peg to the euro (the US dollar) over a peg to some other currency, $\boldsymbol{\beta}_{\mathbf{1}}$ and $\boldsymbol{\beta}_{\mathbf{2}}$ denote the corresponding parameter vectors, $\tau$ is the dissimilarity parameter for the fixed exchange rate options defined as $\tau=\sqrt{1-\rho}$, and $\rho$ 
is the correlation coefficient between the residuals of the random utility from the three options that involve a currency peg ( $c f$ equation (7) below); finally, I denotes the inclusive value of choosing a peg,

$$
I=\ln \left[1+\exp \left(\mathbf{x}_{1}^{\prime} \boldsymbol{\beta}_{1} / \tau\right)+\exp \left(\mathbf{x}_{2}^{\prime} \boldsymbol{\beta}_{2} / \tau\right)\right] .
$$

A FIML approach can be used to estimate the nested logit. Define four binary variables, $y_{i j}(j=1, \ldots, 4)$, for each country $i$ such that $y_{i j}=1$ if alternative $j$ is chosen and $y_{i j}=0$ otherwise. Then, the FIML estimator maximizes the log likelihood

$$
\ln \mathrm{L}=\sum_{i=1}^{N} \sum_{j=1}^{4} y_{i j} \ln p_{i j}
$$

with respect to $\boldsymbol{\alpha}, \boldsymbol{\beta}_{\mathbf{1}}, \boldsymbol{\beta}_{\mathbf{2}}$ and $\tau$.

A sufficient condition for the nested logit model to be consistent with an additive random utility model (ARUM) interpretation is $0 \leq \tau \leq 1$ ( $c f$ Börsch-Supan, 1987, p 49). In this case, country $i$ 's utility of choosing alternative $j$ is given by

$$
U_{i j}=V_{i j}+\varepsilon_{i j}
$$

where $\varepsilon_{i j}$ is an iid error and $V_{i j}$ is the deterministic component of country $i$ 's utility. In the present setting, the deterministic component of utility from choosing a floating exchange rate is normalized to zero, $V_{i 4}=0$. For the three options that involve a currency peg,

$$
\begin{aligned}
& V_{i 1}=\mathbf{z}^{\prime} \boldsymbol{\alpha}+\mathbf{x}_{1}^{\prime} \boldsymbol{\beta}_{1}, \\
& V_{i 2}=\mathbf{z}^{\prime} \boldsymbol{\alpha}+\mathbf{x}_{2}^{\prime} \boldsymbol{\beta}_{2}
\end{aligned}
$$

and

$$
V_{i 3}=\mathbf{z}^{\prime} \boldsymbol{\alpha} .
$$

In an ARUM framework, the chosen alternative $j$ is that with the highest utility $U_{i j}$; however, the high utility of alternative $j, U_{i j}$, can simply be due to a large error $\varepsilon_{i j}$ while deterministic utility of another alternative $k, V_{i k}$, may be larger than $V_{i j}$. In such a case, it may be desirable to test whether the deterministic utility $V_{i k}$ of regime $k$ is significantly larger than the deterministic utility $V_{i j}$ of regime $j$ that country $i$ has 
chosen, ie whether the estimated model would suggest a change in the exchange rate regime or the anchor currency for country $i$. A Wald test statistic for

$$
H_{0}: \hat{V}_{i k}-\hat{V}_{i j}=0
$$

against $H_{1}: \hat{V}_{i k}-\hat{V}_{i j}>0$ is given by

$$
W=\frac{\left(\hat{V}_{i k}-\hat{V}_{i j}\right)^{2}}{\operatorname{Var}\left(\hat{V}_{i k}-\hat{V}_{i j}\right)} \sim \chi_{d f=1}^{2}
$$

and

$$
\operatorname{Var}\left(\hat{V}_{i k}-\hat{V}_{i j}\right)=\hat{\boldsymbol{\Gamma}}^{\prime} \hat{\boldsymbol{\Sigma}} \hat{\boldsymbol{\Gamma}}
$$

where

$$
\hat{\boldsymbol{\Gamma}}=\left[\left.\frac{\partial\left(V_{i k}-V_{i j}\right)}{\partial \boldsymbol{\theta}}\right|_{\boldsymbol{\theta}=\hat{\boldsymbol{\theta}}}\right],
$$

$\boldsymbol{\theta}=\left(\begin{array}{llll}\boldsymbol{\alpha}^{\prime} & \boldsymbol{\beta}_{1}^{\prime} & \boldsymbol{\beta}_{2}^{\prime} & \tau\end{array}\right)^{\prime}$ and $\hat{\boldsymbol{\Sigma}}$ denotes the estimated covariance matrix of $\boldsymbol{\theta}$.

\section{Explanatory variables}

An estimation of the econometric model (1) to (6) requires a set of explanatory variables for the first-level decision on currency regime choice, the vector $\mathbf{z}$, and a set of explanatory variables for the second-level decision on anchor currency choice, the vectors $\mathbf{x}_{1}$ and $\mathbf{x}_{\mathbf{2}}$. The objective of the econometric model is to investigate the effects of the fundamental long-term structural determinants of anchor currency choice. This suggests considering, in particular, variables which are related to optimum currency area (OCA) theory. ${ }^{5}$ OCA theory, which goes back to the seminal works of Mundell (1961) and McKinnon (1963), has been explored in several empirical studies on exchange rate regime choice. Overviews of this literature, which examines variables

\footnotetext{
${ }^{5}$ In studies such as Poirson (2001), Juhn and Mauro (2002) and von Hagen and Zhou (2007), the list of explanatory variables is extended beyond OCA criteria also to include political factors and variables related to the importance of real versus nominal shocks. These variables cannot contribute, however, to an explanation of anchor currency choice. Moreover, Levy-Yeyati et al (2010) have demonstrated the exclusive relevance of OCA criteria for the regime choice of both industrialized and non-industrial countries. Finally, we follow Alesina et al (2002) in ignoring variables related to financial markets and Klein and Shambaugh (2010, p 87) in ignoring macroeconomic variables such as inflation or the volatility of the real exchange rate that could be highly endogenous to the exchange rate regime choice.
} 
that may be included in vector $\mathbf{z}$, is given inter alia by Klein and Shambaugh (2010) as well as von Hagen and Zhou (2007). A recent study by Meissner and Oomes (2009) specifically considers determinants of anchor currency choice in the era prior to the introduction of the euro, ie variables that may be included in vectors $\mathbf{x}_{\mathbf{1}}$ and $\mathbf{x}_{\mathbf{2}}$.

Considering first the determinants of currency regime choice (vector $\mathbf{z}$ ), the most famous insight of OCA theory is that a high degree of international economic integration in goods and factor markets reduces the costs of limiting exchange rate flexibility and raises a peg's benefits. An often-used explanatory variable in this context is (the log of) real GDP expressed in purchasing power parities. ${ }^{6}$ There is less of a necessity for large economies to engage in trade in order to obtain goods. Moreover, the scope for an independent monetary policy is often very limited for small economies, so that for them the opportunity costs of a peg are low. Therefore, optimum currency theory would suggest that a higher real GDP reduces the utility from a peg in equations (8) to (10), which amounts to a negative sign of the corresponding $\alpha$ parameter. $^{7}$

Another OCA hypothesis first put forward by Kenen (1969) is that the gains from a peg are relatively high for a country whose production and/or consumption is highly diversified. A variable that may be used to approximate the degree of product differentiation within an economy is (the log of) real per capita GDP expressed in purchasing power parities. Consumption will be clearly more differentiated in richer economies; while this may also be true of production, some oil-exporting economies, at least, will deviate from the rule. As shown below, the analysis controls for such cases. In sum, the hypothesis suggests a positive $\alpha$ coefficient.

Two further variables have been used in robustness checks not shown in the paper: trade openness (the ratio of imports plus exports per GDP) has been added as a more specific measure of a country's general international trade integration. Since the estimated parameters were always insignificant, openness has been dropped from the baseline specification. As an alternative to real GDP, population has been used in some

\footnotetext{
${ }^{6}$ A description of data sources for the explanatory variables is given in Appendix 2.

${ }^{7}$ Note that the sign of the $\alpha$ coefficients is equal to that of the corresponding marginal effects because the first decision level (peg versus float) of the nested logit has just two alternatives. The same is true of all the $\boldsymbol{\beta}_{\mathbf{1}}$ and $\boldsymbol{\beta}_{\mathbf{2}}$ coefficients of those variables that enter either vector $\mathbf{x}_{\mathbf{1}}$ or vector $\mathbf{x}_{\mathbf{2}}$ but not both.
} 
specifications. The results were always virtually identical to those with real GDP, and are therefore not reported.

Turning to the determinants of anchor currency choice (vectors $\mathbf{x}_{1}$ and $\mathbf{x}_{2}$ ), the complement to general trade openness is trade integration within a currency bloc. While trade integration affects the suitability for entering a peg in general, trade integration within a given bloc determines the appropriateness of pegging to a currency of this specific bloc. Meissner and Oomes (2009) identify this variable as a central determinant of anchor currency choice in the post Bretton Woods era. It is important to note that it is not simply trade with the country that issues the anchor currency but trade with all the bloc members that is expected to govern anchor currency decisions.

Trade integration with a given currency bloc is measured as trade of country $i$ at time $t$ with all the (other) countries that belong to the bloc at time $t$ as a fraction of country $i$ 's total trade. Given the data on anchor currency choice at time $t$, on exports $X$ to all destination countries $k$ and on imports $M$ from all origin countries $k$, the trade share $S$ of country $i$ with the US dollar (USD) bloc at time $t$ is computed as

$$
S_{i, t}^{U S D}=\frac{\sum_{k \in U S D(t)} X_{i, k, t}}{\sum_{k} X_{i, k, t}} \cdot \frac{\sum_{k} X_{i, k, t}}{\sum_{k} X_{i, k, t}+\sum_{k} M_{i, k, t}}+\frac{\sum_{k \in U S D(t)} M_{i, k, t}}{\sum_{k} M_{i, k, t}} \cdot\left(\begin{array}{c}
\sum_{k} X_{i, k, t} \\
\sum_{k} X_{i, k, t}+\sum_{k} M_{i, k, t}
\end{array}\right)
$$

and the trade share with the euro bloc analogously. For each country, such trade shares have been computed for both blocs for each of the years 1999 to 2008. The trade share for the euro bloc is included in vector $\mathbf{x}_{1}$ and the trade share for the dollar bloc in vector $\mathbf{x}_{2}$. This implies, as equations (8) and (9) show, that the trade share for the euro bloc affects the country's utility from choosing a euro peg in comparison with a peg to a currency other than the euro or the US dollar (but not the utility from choosing a dollar peg), while the trade share for the dollar bloc affects only the country's utility from choosing a US dollar peg. In both cases, theory would suggest a positive coefficient. The issue of potential endogeneity is dealt with in section 5.4.

The log of great circle distance between a given country's capital and the location of the central monetary policy authority of each currency bloc is used as a second determinant of anchor currency choice. For several reasons, it is to be expected that a small distance raises the relative utility from pegging a currency to the corresponding 
bloc's anchor currency. First, a small distance implies low transportation costs and thus raises the potential for trade. ${ }^{8}$ Second, a small distance is favourable to a high degree of factor, especially labour, mobility between two locations and thus comes close to reflecting Mundell's (1961) original idea. Third, co-movements of business cycles, an important factor in models such as that of Alesina and Barro (2002), will probably be more symmetric in economies which are located close to each other. Fourth, consumption patterns will probably be more similar in nearby countries, a property which, according to Corsetti (2010), is also conducive to a peg. Fifth, neighbouring populations may also have similar preferences concerning the conduct of monetary policy, a criterion for the desirability of a fixed exchange rate which has been proposed by Haberler (1970). Cultural proximity, for instance a common language, finally supports several of the above criteria. For all these reason, log distance to Frankfurt has been included in vector $\mathbf{x}_{1}$ and log distance to Washington, DC, in vector $\mathbf{x}_{2}$. Both coefficients should be negative.

A further potential determinant of anchor currency choice is the percentage of net oil exports in total exports. Since oil is invoiced in US dollars, a dollar peg would stabilize export, and thus public, revenues of oil exporters. This variable may also serve as a control for the caveat mentioned when dealing with per capita GDP. It is important to use net oil exports because this excludes countries like Singapore - which do not pump oil but have large capacities for refining it - from being treated as oil exporters. This variable is set to zero for all net oil importers. It is included in both $\mathbf{x}_{\mathbf{1}}$ and $\mathbf{x}_{\mathbf{2}}$ because a high percentage of net oil exports might be expected to increase the probability of choosing a dollar peg while decreasing the probability of choosing a euro peg.

As a final explanatory variable, a colony dummy has been used. The dummy is set to one if the country or territory in question is currently or has been governed by one of the euro bloc countries. ${ }^{9}$ Colonial relations from the period before 1960 are ignored. Klein and Shambaugh (2010) suggest that former colonial ruler countries may maintain

\footnotetext{
${ }^{8}$ Therefore, the distance variable is, of course, negatively correlated with the corresponding trade share variable. However, the correlation coefficients in our sample are always far from being seriously close to -1 .

${ }^{9}$ A similar dummy variable has been constructed for the US dollar bloc. However, all the former and present US colonies drop out of the sample because of a lack of data on some other explanatory variable.
} 
ties with their former colonies by providing them with foreign aid that could mitigate business cycles. According to Kenen (1969), such a fiscal transfer system reduces the disutility from binding monetary policy to a foreign authority. Another reason for former colonies to maintain such a peg could be a strategy to attract tourism from the former colonial ruler country, where often the same language is spoken. The dummy which enters vector $\mathbf{x}_{\mathbf{1}}$ is accordingly expected to have a positive $\beta$ coefficient.

The estimated probabilities merely reflect the structural suitability of a country for choosing a specific exchange rate regime and/or currency anchor. Even if a country is found to fundamentally derive a high utility from pegging to a given anchor currency, this does not guarantee a successful maintenance of the peg. As a minimum requirement, the country additionally needs to pursue monetary, fiscal, and wage policies which are adequate for the peg.

\section{Results}

\subsection{Estimation results for coefficients of the baseline specification}

The econometric model (1) to (6) can be estimated either cross-sectionally for each year separately or as a pool. However, the gain in information from pooling the data will probably be rather small because most of the independent variables as well as the dependent one do not vary much over time, if at all. In Table 1, estimation results for the coefficients of both cross-section and pooled estimations are shown. In the pooled estimation, robust standard errors have been obtained by clustering observations by countries. The cross-sectional view is focused on the first and the last years of the sample, 1999 and 2008, respectively. Results for the other years are shown in Appendix 3. In a non-linear model like the present one, the sample averages of the marginal effects may be more instructive than the coefficient estimates, especially concerning their economic significance. These marginal effects of each variable on each alternative are therefore presented in Table $2 .^{10}$

Tables 1 and 2 show that the selected explanatory variables, which are predominantly related to classical OCA criteria, contribute significantly to explaining

\footnotetext{
${ }^{10}$ Limited data availability for the explanatory variables restricts the sample to 157 to 167 countries per year. Apart from Hong Kong, no other dependent territories are included. The USA and Germany, as the base countries for the US dollar bloc and the euro bloc, respectively, are also left out of the sample.
} 
exchange rate regime and anchor currency choice. The signs of all the effects correspond to their expected values. The probability of choosing a fixed exchange rate is low if a country's real GDP is relatively high, and it is high if the country is relatively rich in terms of real GDP per capita. Given that a country decides on a peg, the probability of choosing the euro as anchor currency increases if a country trades extensively with euro bloc members and it decreases with the distance of the country's capital to the location of the European Monetary Union's central bank, Frankfurt am Main. Analogously, having a large trade share with members of the dollar bloc raises a country's probability of belonging to the bloc itself, and being located far from Washington, DC, reduces this probability. Finally, being a present or former colony of one of the euro bloc members considerably raises the probability of using the euro as anchor currency.

Most of the coefficients are highly significant. An exception to this is the coefficient for the distance to Washington, DC, whose sign coincides with theoretical predictions in each of the regressions, but it is weakly significant at best (in the years 2000, 2002 and 2003). This suggests that the US dollar is used as an anchor currency on a global scale, while the euro is more of regional importance as anchor currency. On the face of it, this supports similar observations mentioned in various issues of the ECB's annual publication "The international role of the euro". However, the result needs to be qualified to some degree, as will be seen in section 5.3 .

The other variable whose statistical significance is doubtful is the share of net oil exports in total exports. Since this variable is included as a regressor in both the euro and the US dollar peg equations, the isolated consideration of each of the two coefficients might not reflect the variable's importance. Therefore, a Wald test on the equality of the two estimated parameters has been performed ( $c f$ Table 1 ). The equality hypothesis is weakly rejected in the 1999 and 2008 regressions, but cannot be rejected in the pooled regression. Although the probability of choosing the US dollar as anchor currency is generally found to rise and that of the euro to fall if oil accounts for a larger percentage of a country's net exports ( $c f$ Table 2 ), the validity of the relationship remains largely unconfirmed. This is consistent with the results of Rafiq (2011), who shows that the benefits of a dollar peg for oil-exporting economies are doubtful, because the peg does not insulate them from terms-of-trade shocks. 
The dissimilarity parameter $\tau$ is estimated to lie in the range of 0.2 (in 2002) and 0.5 (in 2008). Likelihood ratio tests always firmly reject the hypothesis that $\tau$ equals 1 . This implies that a simple multinomial logit approach without any nesting structure would have been inappropriate, and the use of the current nested logit structure is confirmed. The fact that $\tau$ always lies in the interval $[0 ; 1]$ implies, moreover, that the currently observed pattern of exchange rate regime and anchor currency choice can be interpreted as an outcome of an additive random utility maximisation on the part of the countries in the sample where the utility functions are defined as in (7) to (10) and $V_{i 4}=0$.

\subsection{The distribution of the estimated probabilities and implications for the exchange rate regime choice of selected countries}

Figures 5 and 6 give an impression of the distribution of the estimated probabilities of choosing currency regime options. Figure 5 relates to the most recent, 2008 regression. Figure 6 also depicts the result for the most recent observation for each country, again mostly that of 2008, but is based on the regression that uses pooled data for 1999-2008. In both figures, each point represents one country, and its location in the large triangle reflects the combined estimated probabilities of choosing a dollar peg, a euro peg or a regime of floating exchange rates. If estimation results suggest a $100 \%$ probability of choosing a float, the point is located at the top corner of the triangle; if the probability of choosing a US dollar (euro) peg is $100 \%$, the point is located at the lower left-hand side (right-hand side) corner of the triangle. ${ }^{11}$ More precisely, assume that each of the three corners of the equilateral large triangle is located at a unit distance from the triangle's geometric centre. Then, the coordinates of a point for country $i$ are given by

$$
\left[\left(\hat{p}_{i 1}-\hat{p}_{i 2}\right) \cdot \cos (\pi / 6) ; \quad \hat{p}_{i 4}-\left(\hat{p}_{i 1}+\hat{p}_{i 2}\right) \cdot \sin (\pi / 6)\right]
$$

\footnotetext{
${ }^{11}$ The two figures ignore one of the regime options of our classification: the peg to a currency other than the US dollar and the euro and the corresponding probabilities $p_{i 3}$. The reason for the exclusion of this alternative is that, being a base category for the peg regimes, it has not been explicitly modelled. A peg to the South African rand, for instance, should include at least the distance to Pretoria and the share of trade with South Africa as explanatory variables. Since there are very few observations for such a peg, this is obviously not possible. For the countries that peg to a currency basket, which are also assigned to category 3, another problem arises: Their basket usually includes a significant amount of US dollars and euros, which the analysis has not been accounted for either. Thus, the estimated probabilities for this category will not be particularly meaningful, and are therefore discarded from the figures.
} 
where $p_{i j}$ is given by equations (1), (2), and (4). The shape and colour of the points indicate the currently chosen regimes: a brown dot for a float, a green triangle for a peg to the US dollar, and a blue diamond for a peg to the euro. In an ideal world, the brown dots should therefore be located near the top corner of the large triangle, the small green triangles near the lower left-hand side corner, and the blue diamonds near the lower right-hand side corner.

Considering the distribution of probabilities, there are (1) countries that are estimated to belong quite unambiguously to one of the currency blocs or to the "float corner" and (2) countries whose probabilities of choosing either one of the two pegs or a floating exchange rate regime are quite similar. The lack of points in the lower central part of the large triangle implies, however, that, once a country decides on a regime of fixed exchange rates, the estimated model leaves hardly any uncertainty about the question of which anchor currency the country should choose.

Comparing the model's predicted regime choice with the one which is actually observed, the figures suggest that most countries have chosen the predicted currency regime. However, there are some countries for which this is obviously not true. How should these cases be interpreted? While the admissibility of an ARUM interpretation ( $c f$ chapter 5.1) suggests that the country's exchange rate regime and anchor currency choice is based on a rational utility-maximising decision, the random utility from that choice is composed of two parts: first, deterministic utility that is explained by the regressors of the model and, second, an error term. Large errors can occur when important explanatory variables have been ignored. If this is not the case, they may, however, indicate that the countries in question have failed to choose the optimal exchange rate regime.

In order to focus on the relevant cases, a Wald test as described in equations (11) to (14) has been used to determine whether the estimated deterministic utility of an alternative regime is significantly larger than the corresponding utility of the regime that 
is actually chosen. ${ }^{12}$ The countries for which such a result has been found are indicated by their ISO codes in Figures 5 and 6; the ISO codes are tabulated in Appendix 1.

First, there is a group of countries that currently allow their exchange rates to float, for which a peg to the euro would, however, significantly increase their estimated utility. These countries are Switzerland, Iceland (a country that has been considering introducing the euro for some years now), the Czech Republic (being an EU member, it is expected to introduce the euro as soon as it fulfils the relevant criteria), Croatia (already temporarily classified as having a euro peg in 2007), Albania and, according to the pooled regression, also Sweden, another EU member. Moreover, the 2008 (but not the pooled) regression suggests a euro peg for Algeria and Suriname. In these two cases, however, the estimated high utility of choosing a euro peg is due, in particular, to the fact that they used to be colonies of France and the Netherlands, respectively. This appears to be a variable for which the possible benefits of a peg discussed in chapter 4 may accrue especially unevenly across countries.

Given the recent friction in the European Monetary Union (EMU), it may be noted that, according to the estimates, none of the EMU member states would significantly increase its utility by leaving the union. While unsustainable fiscal and wage policies have obviously contributed to problems such as the high sovereign debt yields of countries like Greece, Ireland or Portugal, the fundamental structure of their economies is not at odds with these countries' general decision to use the single currency.

The 2008 regression does not yield cases where a country that is not part of the US dollar bloc is estimated to significantly gain utility from joining the bloc, but the pooled regression does: the Seychelles, Jamaica (one of the very few countries in the West Indies that is not part of the bloc yet), Canada and Singapore. The list of countries still supports Alesina et al's (2002) findings according to which “... Latin American countries are by no means a clear dollarization bloc”. Posen's $(2008,2009)$ claim that the US dollar's importance as anchor currency is evidenced by the fact that several countries which should obviously join the euro bloc refrain from doing so is

\footnotetext{
${ }^{12}$ Instead of using the estimated deterministic utilities, the Wald test can also be applied to determine whether the estimated probabilities differ significantly. The relevant results, which are provided on request, mostly do not differ from those presented here.
} 
corroborated by the present results for the euro bloc. While the 2008 regression results for the dollar bloc also confirm Posen, the panel results suggest that the dollar bloc does not differ from the euro bloc in this respect; the latter results are therefore inconsistent with Posen’s argument.

Finally, there is a group of mostly US dollar bloc countries that - according to either the 2008 or the pooled estimation results or both - would gain significantly from letting their currencies float. These are Zimbabwe, ${ }^{13}$ Malawi, China, Bangladesh, Yemen, Turkmenistan, Jordan, Chad, Kazakhstan and the Lebanon. Because of the USA's long-standing efforts to convince China that it should revalue its renminbi vis-àvis the US dollar and because of China's economic and political weight, the result concerning the renminbi may warrant some explanation. First, the modelled utility of choosing a given regime relies entirely on long-term structural economic determinants. Short-term or political considerations do not play a role. From the model's perspective, however, the case for a floating renminbi is overwhelming. The probability value that the estimated utility of a floating renminbi exceeds the utility from a peg to the US dollar is $100 \%$ in both estimations. These results, however, do not necessarily imply that the renminbi is undervalued or needs to be revalued vis-à-vis the US dollar. A judgement on the revaluation issue requires a methodological approach different from the present one and is discussed inter alia in Cheung et al (2009).

\subsection{Is the US dollar used as an "anchor of last resort"?}

Chapter 2 documents a high degree of fluctuation into and out of the US dollar bloc, which is not recorded for the euro bloc. The multitude of cases in which countries de-peg from the dollar may be due to the fact that the euro was introduced as late as at the start of 1999, whereas the US dollar had already served as an anchor currency for several decades. This would be consistent with a long duration between switches from one regime to another. Alternatively, there may be a group of countries that switch relatively often between regimes and - if they decide to peg their currency - tend to choose the US dollar as anchor currency even though their countries' economic structure may not suggest a dollar peg. They may not be able to maintain the dollar peg

\footnotetext{
${ }^{13}$ Note that Zimbabwe took the suggested decision in 2008 as can be seen from Figure 1. The discrepancy arises because of a lack of explanatory variables for Zimbabwe in the years after 2005, which causes the last observation in the pool to be that of 2005, a year in which the Zimbabwean currency was still classified as being pegged to the US dollar.
} 
because of a lack of suitability or insufficient preparation, or they may not have planned to adhere to the peg for very long right from the outset. In such cases, the function of the US dollar may be termed the "anchor of last resort".

If the US dollar had been used as an "anchor of last resort" for the subgroup of the dollar bloc countries that peg only temporarily to the US dollar, the relevant coefficient estimates for the two subgroups should differ significantly from each other. In particular, the coefficients for the temporary peggers to the US dollar should be largely insignificant in contrast to those of the permanent peggers. Table 3 shows the results for two pooled regressions where the US dollar bloc has been split into the two subgroups. The subgroup of permanent dollar peggers is composed of those countries that have limited the flexibility of their currencies against the US dollar over the entire observation period 1999-2008. All the countries that have had a dollar peg at least in one year of the sample period, but not in all years, are subsumed into the alternative subgroup of temporary dollar peggers. ${ }^{14}$

Column (1) presents results for a regression in which the temporary dollar peggers are excluded from the sample. The pool therefore includes all the countries of the three other regimes plus the permanent dollar peggers. In column (2), in contrast, the permanent dollar peggers are excluded from the sample. It is found that the split into the two subgroups yields quite different coefficient estimates and significance levels for the explanatory variables of the utility of a dollar peg (vector $\mathbf{x}_{2}$ ). For the sample that includes the permanent dollar peggers, the coefficients for distance to Washington, DC, and the share of trade with the dollar bloc countries are significant at a $1 \%$ level and three times as large as in the alternative sample. The Wald tests show clear evidence of net oil exporters favouring a dollar anchor over a euro anchor in the sample that includes the permanent dollar peggers, while the evidence for the sample that includes the temporary dollar peggers is only weak.

In sum, there is clear evidence for the hypothesis that structural economic variables play an important role in the anchor currency choice of countries that peg permanently to the US dollar, whereas these factors are much less important for

${ }^{14}$ Klein and Shambaugh $(2008,2010)$ have already explored the duration of peg spells and the repercussions of dividing fixed exchange rate regimes into "long pegs" and "short pegs". However, they did not distinguish between different anchor currencies. 
countries that peg only temporarily to the US dollar. This supports the idea that temporarily pegging countries use the US dollar as their "anchor of last resort", although the significance of the dollar trade share coefficient shows that even for these countries' currency regime choices, OCA criteria are not entirely meaningless. The usage as "anchor of last resort" is clearly a currency property that still distinguishes the US dollar from the euro. In fact, a comparison of the coefficient estimates for the two subsamples in Table 3 and those for the entire pool in Table 1 suggests that the results for the subgroup of temporary dollar peggers dominates the results for the entire sample.

A final observation qualifies the preliminary conclusion of section 5.1 that the US dollar is used as an anchor currency on a global scale, while the euro is more of regional importance as an anchor currency. This conclusion was based on the insignificance of the distance parameter for the USA. As column (1) demonstrates, however, distance to Washington, DC, is highly significant for the subgroup of permanent dollar peggers. The global role of the US dollar as anchor currency, therefore, depends entirely on the countries that peg their currencies to the US dollar only temporarily. The different geographic extensiveness of the anchor currency status of the US dollar (more global) and the euro (more regional) may thus simply derive from the US dollar's "anchor of last resort” function.

\subsection{Checks for endogeneity}

Most of the variables used in the estimation as determinants will hardly be affected by exchange rate regime and anchor currency choice, the variable to be explained. The trade share, however, might potentially be endogenous to the left-hand side variable. On the basis of a corresponding claim in Frankel and Rose (1997), Rose (2000) and Frankel and Rose (2002) estimate a large positive effect of the membership in a currency union on international trade. This claim has subsequently been challenged, inter alia by Persson (2001) and Bun and Klaassen (2007). Turning from currency unions to the more general case of exchange rate regime choice, neither Alesina and Wagner (2006) nor Levy-Yeyati et al. (2010) find evidence of a causality link from trade to regime choice. The evidence in Meissner and Oomes (2009) is inconclusive. According to Wolf and Ritschel (2011), trade creation effects found in gravity equations 
are mostly spurious, and currency bloc arrangements are endogenous to the pre-existing pattern of trade.

As a first tentative control for endogeneity of trade, the pooled nested logit regression has been re-performed, now using trade shares that are lagged by one year. The estimated coefficients and standard errors, shown in column (1) of Table 4, are nearly identical to those of the baseline pooled regression that uses solely contemporaneous data (cf. Table 1). While this implies that a current peg does not immediately influence trade with countries that belong to the same currency bloc, it may be suspected that such effects accumulate gradually over the years or that they occur mostly in the first few years after the peg has been introduced. In such cases, the method would capture only part of the total effect.

Therefore, a second check for endogeneity has been performed, in which only that observation of a pegging country has been left in the sample that falls in the year in which the country introduced the peg. For these observations, the peg cannot have enhanced trade within the currency bloc yet, because the country had been floating previously. Thus, the trade share must be exogenous to regime choice. The procedure implies, of course, that the observations of the countries that have permanently pegged their currencies over the entire observation period are eliminated from the sample. Since the temporary peggers enter the sample with only one observation (unless they have introduced a peg twice or more often within the sample period), only one of the observations for the permanently floating countries, that of 2004 in the middle of the sample period, has been used as well. In the estimation, the variables "oil export share" and "former or present colony of a euro bloc country" have been eliminated from vector $\mathbf{x}_{1}$ because none of the countries that introduced a peg to the euro during the observation period is a net oil exporter and only one (São Tomé and Príncipe) is a former colony.

The results of the regressions are shown in columns (2) and (3) of Table 4. Column (3) differs from column (2) in that re-pegging countries are eliminated from the sample. However, this does not alter the general results. The estimations yield many insignificant coefficients. This is due to the fact that many of the natural peggers are long-term pegging countries that have been eliminated from the sample. However, the coefficient for the share of trade with the euro bloc is very large and also statistically 
significant. Countries that switched from a float to a peg to the euro already had a particularly large share of trade with the euro bloc, a clear sign of the endogeneity of regime choice.

For the US dollar bloc, the situation is estimated to be quite different. The coefficient for the trade share with the dollar bloc is small and insignificant. This may not come as a surprise because the dollar bloc has already been in existence for decades, and countries that engage in intensive trade with the bloc might be expected to have already limited the flexibility of their currency vis-à-vis the dollar before the start of the sample period. The insignificance further confirms the results on the "anchor of last resort" function of the US dollar, according to which many of the countries that have recently introduced a dollar peg have no close affinities with the bloc. Apart from that, Table 4 suggests that net oil exporters have increasingly pegged their currencies to the dollar.

In sum, the second check for endogeneity suggests that there is some evidence for the hypothesis that intensive trade with a given currency bloc is a prerequisite for the decision to join the bloc. This is in line with the results of Wolf and Ritschel (2011) although it does not, of course, exclude the possibility that a currency anchor further enhances trade with the countries of the bloc.

\section{Some illustrative applications to economic policy}

\subsection{Currency blocs in equilibrium}

Section 5.2 demonstrated that, according to the estimated model, some countries would be able to raise their deterministic utility significantly if they chose to switch their exchange rate regime or currency anchor. Now, apply Alesina and Barro’s (2002) definition of an equilibrium in currency unions to currency blocs and define a currency bloc to be in equilibrium if both the following criteria are fulfilled: (1) None of the countries currently in the bloc is able to raise its estimated utility significantly by leaving the bloc and (2) none of the countries currently outside of the bloc is able to raise its estimated utility significantly by joining the bloc.

What would be the composition of the two major currency blocs in such an equilibrium? The answer to such a question is less trivial than might be thought because the equilibrium is not necessarily attained if all the countries for which a significantly 
suboptimal choice has been computed are simply assumed to adopt the regime that has been estimated to provide the highest utility for them. The reason why this would not necessarily end up in equilibrium is that the trade share with a given bloc changes by definition for most countries and territories in the sample as soon as a country enters or leaves the bloc. As elaborated in Meissner and Oomes (2009), the process of pegging or de-pegging of one country's currency exerts a network externality on all the others. If a country $i$ adopts a peg to the US dollar, for instance, the utility of a dollar peg rises for all the other countries that trade with $i$ because the enlargement of the dollar bloc has increased their share of trade with this bloc.

As a consequence of the described network externalities, any currency bloc equilibrium is path-dependent. The current regime and anchor currency choice of a country affects the utility of future regime decisions of other countries. On the one hand this stabilises currently dominant currency blocs; ${ }^{15}$ on the other, it implies that a regime switch of a sufficiently large country or group of countries may initiate a cascade of further regime changes of the same type. Path-dependency may thus increase the probability of equilibria which are corner solutions. If, at the start, some countries are assumed to leave a given currency bloc, this may result in an equilibrium where, after a self-reinforcing cascade of exits, the bloc is entirely dissolved. If some countries are, instead, assumed to join a given bloc, an equilibrium may result where all the countries in the world are clustered in this bloc.

Because of the path-dependency, any calculation of a currency bloc equilibrium, as is suggested by the estimated model, depends on the chosen algorithm for regime adjustment. This section presents results for the following algorithm where, in the first round, the trade shares that are used in the computations are based on the current regime and anchor currency choices.

1) Given the estimation results, equations (8) and (9) as well as $V_{i 4}=0$ are used to compute for each country the deterministic utility of having flexible exchange rates, adopting the US dollar as anchor currency or pegging the currency to the

\footnotetext{
${ }^{15}$ In this sense, “the dollar has the advantage of incumbency”, as Eichengreen (2011, p 124) puts it.
} 
euro. ${ }^{16}$ Subsequently, it is determined for each country whether a regime different from the one presently in place yields an increase in utility.

2) If this is the case, Wald tests along the lines of equations (11) - (14) are employed to determine whether the utility gain from switching to another regime or anchor currency is significantly different from zero. In line with convention, significance is evaluated at a $5 \%$ level. The results for the first two steps have already been applied to current regime choices in section 5.2.

3) Given the pool of countries selected in step 2, the algorithm identifies that country for which the computed $p$-value is the lowest, ie for which there is the highest probability that a change in the exchange rate regime or currency anchor would increase utility.

4) It is assumed that the country selected in step 3 adopts the regime or anchor that has been estimated as being the optimal one in terms of utility.

5) Step 4 has changed the composition of at least one of the currency blocs. Given the new currency bloc composition, equation (15) and an equivalent equation for the euro bloc have been used, therefore, to calculate trade shares for each country with each of the blocs anew.

6) Based on the new trade shares, the loop re-starts in step 1 by computing deterministic utilities for each country. The loop stops if the currency bloc equilibrium, as defined above, is reached.

In short, the basic mechanism of the algorithm is that, in each round, that country is assumed to adopt a new regime for which the probability of the regime shift increasing the estimated utility is highest among all countries, given that this probability is greater than 95\%. Tables 5 and 6 show the path to the currency bloc equilibrium that the algorithm yields. Table 5 relates to the most recent 2008 regression, while Table 6 is based on the regression that uses pooled data for 1999-2008. Therefore, Figure 5 reflects the situation at the start of the path shown in Table 5 and Figure 6 the situation at the start of the path shown in Table 6.

A comparison of Table 5 and Figure 5 reveals that, in spite of the pathdependency, each of the countries initially estimated to gain significantly from a change

\footnotetext{
${ }^{16}$ For reasons given in footnote 10 , pegs to currencies other than the US dollar and the euro are ignored in the calculations.
} 
away from its 2008 currency regime has adopted the utility-maximising regime in the new equilibrium. However, there are three countries for which path-dependency plays a role. Their utility gain of switching the currency regime has been raised so much as a result of the change in the regime of some other countries that it became significant in the course of adjustment to the equilibrium. These countries are Djibouti, for which the utility gain of a change from a dollar to a euro peg becomes significant as soon as China leaves the US dollar bloc (in round 2), ${ }^{17}$ Hungary, for which the utility of a peg to the euro significantly exceeds the utility of its present float as soon as the Czech Republic enters the euro bloc (round 9), and Serbia, for which the same is true starting with Croatia's adoption of a euro peg (round 10).

It might have been expected that the impact of a change in the currency bloc affiliation of a country as large as China noticeably changes relative utility in more countries than just in tiny Djibouti. For the pooled regression (Table 6 and Figure 6), this is actually the case. According to the pool estimates, Canada's and Singapore's utility gains from joining the dollar bloc become insignificant as soon as China starts floating the renminbi. At the same time, the utility gain of a switch from a dollar peg to floating exchange rates becomes significant for Angola and Jordan. The results show that path-dependency's importance should not be overstated nor can it be ignored. As with the 2008 vintage-based estimates, Hungary and Serbia, respectively, are drawn into the euro bloc by Croatia's and the Czech Republic's adoption of a euro peg. In the pool, the same happens to Norway as soon as Sweden joins the euro bloc.

A currency bloc equilibrium is reached after 17 rounds (Table 5) and after 21 rounds (Table 6), respectively. The equilibrium is not a corner solution, that is the two currency blocs still exist and the number of countries with flexible exchange rates has hardly changed. However, the US dollar bloc is smaller in equilibrium than at present. In terms of GDP, this is overwhelmingly due to China's move to flexible exchange rates. In contrast to the contraction of the dollar bloc, the euro bloc has grown in the course of adjustment to the equilibrium, primarily because further European countries

\footnotetext{
${ }^{17}$ Technically speaking, Djibouti's $p$-value of the Wald test on the equality of the two regimes falls below the $5 \%$ significance level. Note that this does not imply that Djibouti should be the next to switch its regime. In fact, the regime switch does not occur until round 15 . This is because, after round 2, there are still plenty of other countries for which the utility gain from changing their currency regime is still higher than Djibouti's, $i e$ their corresponding $p$-value is lower than Djibouti's.
} 
have adopted a euro peg. This does not imply, however, that countries have switched directly from a dollar peg to a euro peg. Instead, countries that abandoned a dollar peg have usually turned to a float while previously floating countries have adopted a euro peg. According to both the 2008 and the pool estimates, the US dollar bloc is, in equilibrium, 1.2 times as large as the euro bloc as measured in GDP terms.

If the path towards equilibrium raises utility of some countries significantly, as the computations suggest, it might be asked which factors block the adjustment in reality. A potentially important factor may be political inertia. If the authorities' choice of a currency regime is based on long-term considerations like those examined here, they can expect the regime to remain optimal for many years or even decades, because the variables that affect utility of a regime move only slowly. The issue of currency regime choice may thus move out of the focus of the authorities' attention. Another reason for the difference between the present pattern of regime choice and the equilibrium may be short-term considerations. Countries whose authorities are unable to stabilise inflation may need a currency anchor even if long-term considerations suggest this is suboptimal ( $c f$ the "anchor of last resort" discussion in section 5.3). Capital controls may be able to alleviate for some time the disutility from having chosen a suboptimal regime. In this context, it should be highlighted that our parsimonious specification of the explanatory variables may have ignored further economic or political factors of regime choice, the inclusion of which would have changed the equilibrium.

\subsection{Effects of counterfactual economic policy decisions}

An investigation into counterfactual policy decisions requires a baseline scenario for comparative purposes. In the present study, two alternatives lend themselves to serve as such; first, the estimated utilities computed for the year 2008 situation either using the 2008-vintage data or the pool data ( $c f$ Figures 5 and 6); second, the two corresponding currency bloc equilibria. Below, the equilibria are used as baseline scenarios, ie the counterfactuals consider the effect of a policy measure on the path to the equilibrium as is shown in Tables 5 and 6, respectively. Technically, the policy measure is first introduced, after which the algorithm described in the previous section is run until the currency bloc equilibrium is reached. 


\subsubsection{A country deliberately joins one of the currency blocs}

Some of the European Union's member states have not pegged their currencies to the euro, yet. Among these are larger countries, such as the Czech Republic, Poland, Sweden and the UK. Under the Treaty on the Functioning of the European Union, however, it is assumed that member states will introduce the euro as soon as the European Council of Heads of State or of Government decides that they fulfil the relevant convergence criteria. ${ }^{18}$ In this context, the prospects of joining the monetary union are often discussed in these countries. Before being able to introduce the euro, countries must have stabilized their currencies vis-à-vis the euro for at least two years. Counterfactuals investigate whether the adoption of a peg to the euro by one of these countries eventually raises the estimated utility of a peg for another country beyond the 95\% significance level.

In the baseline scenarios, the Czech Republic joins the euro bloc on the path to the equilibrium anyway ( $c f$ Tables 5 and 6). The counterfactual of a deliberate adoption of a euro peg in the Czech Republic thus amounts to the question of whether the equilibrium changes if the Czech Republic is the first country assumed to switch to a new regime. It turns out that this is not the case.

For Poland, Sweden and the UK, the situation in the baseline equilibrium is different. In the case of Poland and Sweden, the estimated probability of joining the euro bloc is higher than that of any other option including their current float. For the UK, the same is true if the equilibrium is based on the pool estimates, but not if it is based on 2008 data estimates. Neither for Poland nor for the UK, however, does the probability of an increase in utility in the case of an adoption of a euro peg exceed 95\%.

If Sweden is assumed to deliberately peg its currency to the euro, the 2008 data estimates suggest that Norway should do so as well. If either Poland or the UK joined the euro bloc, both Sweden and Norway should enter a euro peg as well. The equilibrium based on the pool estimates, however, is not affected by any of these counterfactuals because Sweden and Norway are already part of the euro bloc in this baseline equilibrium ( $c f$ Table 6).

\footnotetext{
${ }^{18}$ The UK and Denmark negotiated an exemption from this rule.
} 
Although there is no corresponding political initiative, the counterfactuals above might prompt the question of what happens if one of the NAFTA countries Canada or Mexico pegs its currency to the US dollar. It is found that such a step would usually not affect the baseline equilibria. As the only exception, the adoption of a dollar peg by Mexico alters the equilibrium based on the pool estimates in the sense that Canada joins the dollar bloc as well.

\subsubsection{Oil-exporting countries stop using the US dollar as invoice currency}

Currently, the US dollar is used as the invoice currency for oil exports. In recent years, there have been discussions in some countries about whether this could or should be changed. Until now, a majority of OPEC countries have rejected the idea ( $c f$ Eichengreen, 2011, p 123). Nevertheless, Khan (2009) reports for the Middle East, where many countries peg their currencies to the dollar and, at the same time, are net oil exporters, that "there is considerable discussion in the region about reducing the dominance of the dollar and increasing the relative importance of the euro” (p 139). In an analysis of this issue, Louis et al (2010) find that an anchor to a currency basket may be superior to a dollar peg for the countries of the Gulf Cooperation Council. It may therefore be of interest to investigate the repercussions of a counterfactual in which oilexporting countries stop using the dollar as the invoice currency. Technically, this has been done, first, by setting the parameters of the percentage of oil in total exports and its variances and covariances to zero and, then, re-computing the new currency bloc equilibrium.

Since the significance of the net oil export parameters in the baseline estimates is weak at best, it might be expected that the counterfactual arrives at virtually the same equilibrium as the baseline scenario. Such a conjecture is supported by the results for the pooled estimates, where the switch in invoice currency simply raises Azerbaijan's estimated utility gain of de-pegging its currency from the dollar to significant levels. Moreover, Chad has chosen to float its currency instead of pegging it to the US dollar in the new counterfactual equilibrium. When the 2008 data estimates are used, the repercussions of a change in the oil trade invoice currency are more severe. The new counterfactual equilibrium differs from the baseline equilibrium by the fact that not only Azerbaijan has chosen to de-peg its currency from the dollar and let it float but also 
Ecuador, Kazakhstan and Saudi Arabia. Angola is computed to switch directly from the US dollar to the euro bloc.

\subsubsection{Former colonial ties no longer bind}

In the estimations, the parameter of the dummy for former dependency on one of the euro bloc countries is highly significant. However, for most countries, several decades have passed since they obtained political independence. Network effects will have played a role in maintaining ties between former colony and colonial power. The counterfactual of this section assumes that these ties no longer bind. Technically, a new equilibrium is computed much like in the previous section after having set the parameter and covariances of the colony dummy to zero. In the resulting counterfactual equilibrium, nearly all the African countries that presently peg their currencies to the euro have left the euro bloc. ${ }^{19}$ Most of these countries have adopted a regime of flexible exchange rates. The Republic of the Congo and Gabon, both of which are net oil exporters, have switched directly from a euro peg to a dollar peg.

\subsubsection{The potential of China's renminbi to serve as the core of a third major currency bloc}

The rapidly rising importance of China in the global economy has sparked discussions on a bigger international role for the Chinese currency, the renminbi. The Chinese authorities themselves have contributed to the discussion. In March 2009, for instance, Governor Zhou of the People's Bank of China gave a speech, in which he proposed a reform of the international monetary system. Eichengreen (2011, pp 144145) cites inter alia "China's currency swap agreements ... as a way for it to signal its ambitions". This suggests exploring the potential of the renminbi to become the anchor currency for a group of countries and, thus, the core of a new currency bloc. As before, the counterfactual focuses on whether the economic structure of the country considered is conducive to a renminbi peg. For the renminbi to become an anchor currency at all, however, additional adjustments on the part of the Chinese authorities would obviously be necessary, notably the establishment of renminbi convertibility.

For a world with three, rather than two currency blocs, the model requires some slight adjustments. The decision tree in Figure 4 is expanded by adding a fourth branch

\footnotetext{
${ }^{19}$ The only exceptions are Equatorial Guinea and the island states of Cape Verde and São Tomé and Príncipe. The result is independent of the estimates used for their calculation.
} 
called "peg to the renminbi" for the category "anchor currency choice". The econometric model (1) - (5) is extended by a further equation

$$
p_{i, p e g_{-} r m b}=p_{i 5}=p_{i P} \times p_{i 5 \mid P}=\frac{\exp \left(\mathbf{z}^{\prime} \boldsymbol{\alpha}+\tau \cdot I\right)}{1+\exp \left(\mathbf{z}^{\prime} \boldsymbol{\alpha}+\tau \cdot I\right)} \cdot \frac{\exp \left(\mathbf{x}_{\mathbf{5}}^{\prime} \boldsymbol{\beta}_{\mathbf{5}} / \tau\right)}{\exp (I)}
$$

and the inclusive value defined in equation (5) is replaced for (1) - (4) and (17) by

$$
I=\ln \left[1+\exp \left(\mathbf{x}_{1}^{\prime} \boldsymbol{\beta}_{1} / \tau\right)+\exp \left(\mathbf{x}_{2}^{\prime} \boldsymbol{\beta}_{2} / \tau\right)+\exp \left(\mathbf{x}_{5}^{\prime} \boldsymbol{\beta}_{5} / \tau\right)\right],
$$

where $\mathbf{x}_{\mathbf{5}}$ denotes the vector of explanatory variables for choosing the renminbi as anchor currency, $\boldsymbol{\beta}_{\mathbf{5}}$ is the corresponding parameter vector and $p_{i 5}$ is the probability for country $i$ of choosing a renminbi peg.

The set of explanatory variables included in vector $\mathbf{x}_{\mathbf{5}}$ is compiled along the lines of those of vectors $\mathbf{x}_{\mathbf{1}}$ and $\mathbf{x}_{\mathbf{2}}$. Vector $\mathbf{x}_{\mathbf{5}}$ thus includes for each country its share of net oil exports in total exports, the great circle distance between its capital and Beijing, its trade with China as a percentage of total trade, and a colony dummy which is set to 1 for Hong Kong and 0 elsewhere. Since a counterfactual is considered, the parameters in vector $\boldsymbol{\beta}_{5}$ cannot be estimated, but must be imposed instead. Below, results of a counterfactual are presented, in which the estimated parameters for the euro bloc are imposed on China, $\boldsymbol{\beta}_{\mathbf{5}}=\hat{\boldsymbol{\beta}}_{\mathbf{1}}$. Modelling the renminbi analogously to the euro might be rather plausible because the Chinese currency would be in a situation similar to that of the euro, a contender for the role of the incumbent, the US dollar. Alternatively, the renminbi could have been parameterised along the lines of the dollar, imposing the estimated distance and trade share parameters for the dollar bloc on $\boldsymbol{\beta}_{\mathbf{5}}$. It turned out, however, that both exercises yield very similar results, which, of course, is a signal of their robustness.

The present counterfactual also requires a modification of the algorithm that determines the currency bloc equilibrium. This is necessary because there are no compelling values available that could be imposed on the covariances between the parameters in $\boldsymbol{\beta}_{5}$ and the other parameters of the model. This implies that the covariance matrix $\hat{\boldsymbol{\Sigma}}$ in equation (13) cannot be determined and, consequently, a Wald test cannot be performed. In the previous exercises, however, the algorithm assumed that a country switches its currency regime only if the Wald test indicates at least a 95\% probability 
that the switch will raise the country's utility. Since the application of the Wald test is impossible in the present counterfactual, the algorithm has been adjusted to allow a switch of the currency regime as long as the probability of country $i$ choosing an alternative regime (ie pegging its currency to the renminbi) is higher than the probability of keeping its current currency regime. Note that this is a much looser condition than the one used so far. An equilibrium might therefore be expected where a relatively large group of countries has joined the renminbi bloc.

However, in spite of the lower hurdle, results suggest the opposite. Irrespective of whether the pool estimates or the 2008 data estimates are used, the only economy that has pegged its currency to the renminbi in the counterfactual equilibrium is Hong Kong. How does the prospect of a continuation of the increase in trade between China and its partners relative to trade in the rest of the world affect this result? In order to assess this question, exports and imports of China have been progressively multiplied, while the trade of the rest of the world has been kept constant. It turns out that, apart from Hong Kong, only Mongolia and the Solomon Islands have joined the renminbi bloc in a new equilibrium, even if the trade of China has been assumed to rise to five times its 2008 magnitude relative to the rest of the world. Again, this result is independent of the set of estimates used in the calculations. In sum, the counterfactuals suggest that, first, the present potential for a renminbi currency bloc is very small, even if convertibility of the renminbi were to be established, and second, that China still has a long way to go before the renminbi obtains the potential to rival the US dollar as an anchor currency.

\section{Conclusions}

In the introduction, three sets of questions on currency blocs were posed that have been tackled successively in the study. The first of these questions simply asked for a description of presently existing currency blocs. It turned out that, in terms of anchor currency status, Eichengreen's (2011) prospect of a world of multiple international currencies has already been attained. At present, two major currency blocs, the US dollar bloc and the euro bloc, coexist with numerous floating currencies. The number of countries and territories that belong to each of the two blocs was the same in 2008. In terms of combined GDP measured in purchasing power parities, the US dollar bloc is around double the size of the euro bloc. This changes considerably, however, as soon as 
China de-pegs its currency from the dollar. In contrast to the euro bloc, there is a high degree of fluctuation into and out of the dollar bloc.

The second set of questions was centred on the determinants of anchor currency choice and the distinctive features of the two currency blocs. The results of a nested logit regression suggest that long-term structural economic variables significantly explain the choice between a floating and a fixed exchange rate regime and, at the same time, the anchor currency choice once a country opted for a peg. Trade integration plays a major role in a country's anchor currency choice in both the dollar bloc and the euro bloc. The distance to the location of the central monetary authority of the two blocs, Washington, DC, and Frankfurt am Main, respectively, is a significant factor for anchor currency choice with regard to the euro bloc, but not the dollar bloc. This might imply that the US dollar is of global importance as an anchor currency and that the euro is not. Separate regressions qualify such a conclusion, however, by showing that this outcome is due entirely to a group of countries that peg their currencies only temporarily to the US dollar.

Addressing the third set of questions, the study computes a currency bloc equilibrium in the spirit of Alesina and Barro (2002). It is found that, in equilibrium, the US dollar bloc is smaller and the euro bloc larger than at present. The equilibrium is characterised by several Asian and African countries having de-pegged from the US dollar and additional European countries having adopted a fixed exchange rate vis-à-vis the euro. In spite of quite substantial differences in the methodological approach, the results are close to those of Alesina et al (2002). Moreover, the calculations suggest that, structurally, the potential for the formation of a renminbi bloc is low. If the estimated structural relations for the euro or the dollar bloc can be taken as a guide, the establishment of convertibility of the renminbi will be only a first step in this direction.

The question remains as to whether the estimated path to the currency bloc equilibrium provides a glimpse into the future. This may be the case if the reason for the deviations of the equilibrium from the present situation is the slow adjustment of currency regimes. Alternatively, factors that have not been included in the analysis could inhibit any adjustment. Concerning the relative weight of the two large currency blocs, two such factors are currently under discussion. Eichengreen (2011, p 130) puts 
forward the idea that an expansion of the international role of the euro is being slowed down by the fact that the euro is a currency without a unified state. As a second reason against a further rise of the euro, Posen $(2008,2009)$ picks up a point made by Strange (1980), claiming that a lack of military power is preventing a further expansion of the euro area. 


\section{References}

Alesina, A, and RJ Barro, 2002, Currency unions, Quarterly Journal of Economics 117, 409-436.

Alesina, A, RJ Barro, and S Tenreyro, 2002, Optimal currency areas, NBER Macroeconomics Annual 17, 301-345.

Alesina, A, and AF Wagner, 2006, Choosing (and reneging on) exchange rate regimes, Journal of the European Economic Association 4, 770-799.

Börsch-Supan, A, 1987, Econometric Analysis of Discrete Choice, Berlin, Springer.

Bun, MJG, and FJGM Klaassen, 2007, The euro effect on trade is not as large as commonly thought, Oxford Bulletin of Economics and Statistics 69, 473-496.

Calvo, GA, and CM Reinhart, 2002, Fear of floating, Quarterly Journal of Economics $117,379-408$.

Cheung, Y-W, MD Chinn, and E Fujii, 2009, Pitfalls in measuring exchange rate misalignment - the yuan and other currencies, Open Economies Review 20, 183206.

Chinn, M, and J Frankel, 2007, Will the euro eventually surpass the dollar as leading international reserve currency?, in RH Clarida (ed), G7 Current Account Imbalances: Sustainability and Adjustment, Chicago, Chicago University Press, 283-335.

Chinn, M, and J Frankel, 2008, Why the euro will rival the dollar, International Finance $11,49-73$.

Cobham, D, 2008, Changing currency alignments: euro versus dollar, Mimeo.

Corsetti, G, 2010, A modern reconsideration of the OCA theory, in M Buti, S Deroose, V Gaspar and JN Martins (eds), The Euro - The First Decade, Cambridge, Cambridge University Press, 143-180.

Deutsche Bundesbank, Exchange Rate Statistics, Statistical Supplement to the Monthly Report 5, various issues.

Dubas, JM, B-J Lee, and NC Mark, 2010, A multinomial logit approach to exchange rate policy classification with an application to growth, Journal of International Money and Finance 29, 1438-1462.

Eichengreen, B, 2011, Exorbitant Privilege - the Rise and Fall of the Dollar, Oxford, Oxford University Press.

European Central Bank, The International Role of the Euro, various issues.

Frankel, JA, and AK Rose, 1997, Is EMU more justifiable ex post than ex ante?, European Economic Review 41, 753-760.

Frankel, J, and A Rose, 2002, An estimate of the effect of common currencies on trade and income, Quarterly Journal of Economics 117, 437-466.

Haberler, G, 1970, The international monetary system: some recent developments and discussions, in GN Halm (ed), Approaches to greater flexibility of exchange rates, Princeton, Princeton University Press, 115-123. 
International Monetary Fund, Annual Report on Exchange Arrangements and Exchange Restrictions, various issues.

Juhn, G, and P Mauro, 2002, Long-run determinants of exchange rate regimes: a simple sensitivity analysis, IMF Working Paper 02/104.

Kenen, PB, 1969, The theory of optimum currency areas: an eclectic view, in RA Mundell and AK Swoboda (eds), Monetary Problems of the International Economy, Chicago, University of Chicago Press, 41-60.

Khan, MS, 2009, Middle east and oil exporters, in J Pisani-Ferry and A Posen (eds), The Euro at Ten: The Next Global Currency?, Washington, Peterson Institute for International Economics, 139-154.

Klein, MW, and JC Shambaugh, 2008, The dynamics of exchange rate regimes: fixes, floats, and flips, Journal of International Economics 75, 70-92.

Klein, MW, and JC Shambaugh, 2010, Exchange Rate Regimes in the Modern Era, Cambridge, MIT Press.

Levy-Yeyati, E, and F Sturzenegger, 2003, To float or to fix: evidence on the impact of exchange rate regimes on growth, American Economic Review 93, 1173-1193.

Levy-Yeyati, E, F Sturzenegger, and I Reggio, 2010, On the endogeneity of exchange rate regimes, European Economic Review 54, 659-677.

Louis, RJ, M Osman, and F. Balli, 2010, Is the US dollar a suitable anchor for the newly proposed GCC currency?, The World Economy 33, 1898-1922.

McFadden, D, 1978, Modelling the choice of residential location, in A Karlqvist, L Lundqvist, F Snickars and JW Weibull (eds), Spatial Interaction Theory and Planning Models, Amsterdam, North-Holland, 75-96.

McFadden, D, 1981, Econometric models of probabilistic choice, in CF Manski and D McFadden (eds), Structural Analysis of Discrete Data with Econometric Applications, Cambridge, MIT Press, 198-272.

McKinnon, RI, 1963, Optimum currency areas, American Economic Review 53, 717725.

Meissner, CM, and N Oomes, 2009, Why do countries peg the way they peg? The determinants of anchor currency choice, Journal of International Money and Finance 28, 522-547.

Mundell, RA, 1961, A theory of optimum currency areas, American Economic Review 51, 657-665.

Papaioannou, E, and R Portes, 2010, The international role of the euro: a status report, in M Buti, S Deroose, V Gaspar and JN Martins (eds), The Euro - The First Decade, Cambridge, Cambridge University Press, 360-407.

Persson, T, 2001, Currency unions and trade: how large is the treatment effect?, Economic Policy 16, 435-448.

Poirson, H, 2001, How do countries choose their exchange rate regime?, IMF Working Paper 01/46. 
Portes, R, and H Rey, 1998, The emergence of the euro as an international currency, Economic Policy 13, 305-343.

Posen, A, 2008, Why the euro will not rival the dollar, International Finance 11, 75100.

Posen, A, 2009, Geopolitical limits to the euro's global role, in J Pisani-Ferry and A Posen (eds), The Euro at Ten: The Next Global Currency?, Washington, Peterson Institute for International Economics, 85-102.

Rafiq, MS, 2011, Sources of economic fluctuations in oil-exporting economies: implications for choice of exchange rate regimes, International Journal of Finance and Economics 16, 70-91.

Reinhart, CM, and KS Rogoff, 2004, The modern history of exchange rate arrangements: a reinterpretation, Quarterly Journal of Economics 119, 1-48.

Rose, AK, 2000, One money, one market: the effect of common currencies on trade, Economic Policy 15, 9-45.

Shambaugh, JC, 2004, The effect of fixed exchange rates on monetary policy, Quarterly Journal of Economics 119, 301-352.

Strange, S, 1980, Germany and the world monetary system, in WL Kohl, and G Basevi (eds), West Germany: a European and Global Power, Lexington, Lexington Books, 45-62.

von Hagen, J, and J Zhou, 2007, The choice of exchange rate regimes in developing countries: a multinomial panel analysis, Journal of International Money and Finance 26, 1071-1094.

Wolf, N, and AO Ritschel, 2011, Endogeneity of currency areas and trade blocs: evidence from a natural experiment, Kyklos 64, 291-312. 


\begin{tabular}{|c|c|c|c|c|c|c|c|c|c|c|c|}
\hline Country & $\begin{array}{l}\text { ISO } \\
\text { code }\end{array}$ & 욤 & ষ্ণ & ס্ & 尺ิ & ஜ̊ & ষ্ণ & $\stackrel{\text { ㅇ }}{\stackrel{\sim}{N}}$ & 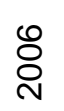 & ঠे & $\begin{array}{l}\infty \\
\stackrel{\sim}{\sim}\end{array}$ \\
\hline Afghanistan & $A F$ & 4 & 4 & 4 & 4 & 4 & 4 & 4 & 4 & 4 & 4 \\
\hline Albania & AL & 4 & 4 & 4 & 4 & 4 & 4 & 4 & 4 & 4 & 4 \\
\hline Algeria & $\mathrm{DZ}$ & 4 & 4 & 4 & 4 & 4 & 4 & 4 & 4 & 4 & 4 \\
\hline American Samoa* & AS & 2 & 2 & 2 & 2 & 2 & 2 & 2 & 2 & 2 & 2 \\
\hline Andorra* & $A D$ & 1 & 1 & 1 & 1 & 1 & 1 & 1 & 1 & 1 & 1 \\
\hline Angola & $\mathrm{AO}$ & 4 & 4 & 4 & 4 & 4 & 4 & 4 & 2 & 2 & 2 \\
\hline Anguilla* & $\mathrm{Al}$ & 2 & 2 & 2 & 2 & 2 & 2 & 2 & 2 & 2 & 2 \\
\hline Antigua Barbuda & $A G$ & 2 & 2 & 2 & 2 & 2 & 2 & 2 & 2 & 2 & 2 \\
\hline Argentina & AR & 2 & 2 & 4 & 4 & 4 & 4 & 4 & 2 & 2 & 4 \\
\hline Armenia & AM & 4 & 4 & 4 & 4 & 4 & 4 & 4 & 4 & 4 & 4 \\
\hline Aruba & AW & 2 & 2 & 2 & 2 & 2 & 2 & 2 & 2 & 2 & 2 \\
\hline Australia & $A U$ & 4 & 4 & 4 & 4 & 4 & 4 & 4 & 4 & 4 & 4 \\
\hline Austria & AT & 1 & 1 & 1 & 1 & 1 & 1 & 1 & 1 & 1 & 1 \\
\hline Azerbaijan & $A Z$ & 4 & 4 & 4 & 4 & 4 & 4 & 2 & 4 & 4 & 2 \\
\hline Bahamas & BS & 2 & 2 & 2 & 2 & 2 & 2 & 2 & 2 & 2 & 2 \\
\hline Bahrain & $\mathrm{BH}$ & 2 & 2 & 2 & 2 & 2 & 2 & 2 & 2 & 2 & 2 \\
\hline Bangladesh & BD & 3 & 3 & 2 & 2 & 4 & 4 & 4 & 4 & 2 & 2 \\
\hline Barbados & BB & 2 & 2 & 2 & 2 & 2 & 2 & 2 & 2 & 2 & 2 \\
\hline Belarus & BY & 4 & 4 & 4 & 4 & 4 & 4 & 2 & 2 & 2 & 3 \\
\hline Belgium & $\mathrm{BE}$ & 1 & 1 & 1 & 1 & 1 & 1 & 1 & 1 & 1 & 1 \\
\hline Belize & $B Z$ & 2 & 2 & 2 & 2 & 2 & 2 & 2 & 2 & 2 & 2 \\
\hline Benin & BJ & 1 & 1 & 1 & 1 & 1 & 1 & 1 & 1 & 1 & 1 \\
\hline Bermuda* & $\mathrm{BM}$ & 2 & 2 & 2 & 2 & 2 & 2 & 2 & 2 & 2 & 2 \\
\hline Bhutan & BT & 3 & 3 & 3 & 3 & 3 & 3 & 3 & 3 & 3 & 3 \\
\hline
\end{tabular}




\begin{tabular}{|c|c|c|c|c|c|c|c|c|c|c|c|}
\hline Country & $\begin{array}{l}\text { ISO } \\
\text { code }\end{array}$ & ஓ & ঃి & ஓ্ণ & ָ̊ & $\stackrel{\overbrace{}}{\check{~}}$ & ষ্ণ & $\stackrel{\circ}{\circ}$ & ஜ̊ & ঠి & $\begin{array}{l}\infty \\
\stackrel{\varnothing}{~}\end{array}$ \\
\hline Bolivia & $\mathrm{BO}$ & 4 & 4 & 4 & 4 & 4 & 4 & 4 & 2 & 4 & 4 \\
\hline Bosnia and Herzegovina & BA & 1 & 1 & 1 & 1 & 1 & 1 & 1 & 1 & 1 & 1 \\
\hline Botswana & BW & 3 & 3 & 3 & 3 & 3 & 4 & 4 & 4 & 4 & 4 \\
\hline Brazil & BR & 4 & 4 & 4 & 4 & 4 & 4 & 4 & 4 & 4 & 4 \\
\hline British Virgin Islands* & VG & 2 & 2 & 2 & 2 & 2 & 2 & 2 & 2 & 2 & 2 \\
\hline Brunei & $\mathrm{BN}$ & 3 & 3 & 3 & 3 & 3 & 3 & 3 & 3 & 3 & 3 \\
\hline Bulgaria & BG & 1 & 1 & 1 & 1 & 1 & 1 & 1 & 1 & 1 & 1 \\
\hline Burkina Faso & $\mathrm{BF}$ & 1 & 1 & 1 & 1 & 1 & 1 & 1 & 1 & 1 & 1 \\
\hline Burundi & $\mathrm{BI}$ & 4 & 4 & 4 & 4 & 4 & 4 & 4 & 4 & 4 & 4 \\
\hline Cambodia & $\mathrm{KH}$ & 4 & 4 & 4 & 4 & 4 & 4 & 4 & 4 & 4 & 4 \\
\hline Cameroon & $\mathrm{CM}$ & 1 & 1 & 1 & 1 & 1 & 1 & 1 & 1 & 1 & 1 \\
\hline Canada & CA & 4 & 4 & 4 & 4 & 4 & 4 & 4 & 4 & 4 & 4 \\
\hline Cape Verde & $\mathrm{CV}$ & 1 & 1 & 1 & 1 & 1 & 1 & 1 & 1 & 1 & 1 \\
\hline Cayman Islands* & KY & 2 & 2 & 2 & 2 & 2 & 2 & 2 & 2 & 2 & 2 \\
\hline Central African Republic & $\mathrm{CF}$ & 1 & 1 & 1 & 1 & 1 & 1 & 1 & 1 & 1 & 1 \\
\hline Chad & TD & 1 & 1 & 1 & 1 & 1 & 1 & 1 & 1 & 1 & 1 \\
\hline Channel Islands* & JE & 3 & 3 & 3 & 3 & 3 & 3 & 3 & 3 & 3 & 3 \\
\hline Chile & $\mathrm{CL}$ & 4 & 4 & 4 & 4 & 4 & 4 & 4 & 4 & 4 & 4 \\
\hline China & $\mathrm{CN}$ & 2 & 2 & 2 & 2 & 2 & 2 & 2 & 4 & 4 & 2 \\
\hline China (Taiwan)* & TW & 4 & 4 & 4 & 4 & 4 & 4 & 4 & 4 & 4 & 4 \\
\hline Colombia & $\mathrm{CO}$ & 4 & 4 & 4 & 4 & 4 & 4 & 4 & 4 & 4 & 4 \\
\hline Comoros & $\mathrm{KM}$ & 1 & 1 & 1 & 1 & 1 & 1 & 1 & 1 & 1 & 1 \\
\hline Congo, Democratic Republic & ZR & 4 & 4 & 4 & 4 & 4 & 4 & 4 & 4 & 4 & 4 \\
\hline Congo, Republic & CG & 1 & 1 & 1 & 1 & 1 & 1 & 1 & 1 & 1 & 1 \\
\hline Cook Islands* & CK & 3 & 3 & 3 & 3 & 3 & 3 & 3 & 3 & 3 & 3 \\
\hline Costa Rica & $\mathrm{CR}$ & 4 & 4 & 4 & 4 & 4 & 4 & 4 & 4 & 4 & 4 \\
\hline Côte d'Ivoire & $\mathrm{Cl}$ & 1 & 1 & 1 & 1 & 1 & 1 & 1 & 1 & 1 & 1 \\
\hline
\end{tabular}




\begin{tabular}{|c|c|c|c|c|c|c|c|c|c|c|c|}
\hline Country & $\begin{array}{l}\text { ISO } \\
\text { code }\end{array}$ & ஓ & ঃ & ఠ్రి & ָ̊ & ஜి & ষ্ণ & ஜ̊ํํ & 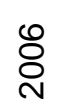 & ঠ্ঠ & $\begin{array}{l}\infty \\
\stackrel{్}{\circ}\end{array}$ \\
\hline Croatia & $\mathrm{HR}$ & 4 & 4 & 4 & 4 & 4 & 4 & 4 & 4 & 1 & 4 \\
\hline Cuba* & $\mathrm{CU}$ & 2 & 2 & 2 & 2 & 2 & 2 & 2 & 2 & 2 & 2 \\
\hline Cyprus & CY & 1 & 1 & 1 & 1 & 1 & 1 & 1 & 1 & 1 & 1 \\
\hline Czech Republic & $C Z$ & 4 & 4 & 4 & 4 & 4 & 4 & 4 & 4 & 4 & 4 \\
\hline Denmark & DK & 1 & 1 & 1 & 1 & 1 & 1 & 1 & 1 & 1 & 1 \\
\hline Djibouti & DJ & 2 & 2 & 2 & 2 & 2 & 2 & 2 & 2 & 2 & 2 \\
\hline Dominica & DM & 2 & 2 & 2 & 2 & 2 & 2 & 2 & 2 & 2 & 2 \\
\hline Dominican Republic & DO & 4 & 4 & 4 & 4 & 4 & 4 & 4 & 4 & 4 & 4 \\
\hline Ecuador & $\mathrm{EC}$ & 2 & 2 & 2 & 2 & 2 & 2 & 2 & 2 & 2 & 2 \\
\hline Egypt & EG & 2 & 2 & 2 & 4 & 4 & 4 & 2 & 2 & 4 & 4 \\
\hline El Salvador & SV & 2 & 2 & 2 & 2 & 2 & 2 & 2 & 2 & 2 & 2 \\
\hline Equatorial Guinea & GQ & 1 & 1 & 1 & 1 & 1 & 1 & 1 & 1 & 1 & 1 \\
\hline Eritrea & ER & 4 & 2 & 2 & 2 & 2 & 2 & 2 & 2 & 2 & 2 \\
\hline Estonia & EE & 1 & 1 & 1 & 1 & 1 & 1 & 1 & 1 & 1 & 1 \\
\hline Ethiopia & ET & 4 & 4 & 4 & 4 & 4 & 4 & 4 & 2 & 4 & 4 \\
\hline Falkland Islands* & FK & 3 & 3 & 3 & 3 & 3 & 3 & 3 & 3 & 3 & 3 \\
\hline Faroe Islands* & FO & 1 & 1 & 1 & 1 & 1 & 1 & 1 & 1 & 1 & 1 \\
\hline Fiji & FJ & 3 & 3 & 3 & 3 & 3 & 3 & 3 & 3 & 3 & 3 \\
\hline Finland & $\mathrm{FI}$ & 1 & 1 & 1 & 1 & 1 & 1 & 1 & 1 & 1 & 1 \\
\hline France & $\mathrm{FR}$ & 1 & 1 & 1 & 1 & 1 & 1 & 1 & 1 & 1 & 1 \\
\hline French Guiana* & GF & 1 & 1 & 1 & 1 & 1 & 1 & 1 & 1 & 1 & 1 \\
\hline French Polynesia* & $\mathrm{PF}$ & 1 & 1 & 1 & 1 & 1 & 1 & 1 & 1 & 1 & 1 \\
\hline Gabon & GA & 1 & 1 & 1 & 1 & 1 & 1 & 1 & 1 & 1 & 1 \\
\hline Gambia & GM & 4 & 4 & 4 & 4 & 4 & 4 & 4 & 4 & 4 & 4 \\
\hline Georgia & GE & 4 & 4 & 4 & 4 & 4 & 4 & 4 & 4 & 4 & 4 \\
\hline Ghana & $\mathrm{GH}$ & 4 & 4 & 4 & 4 & 4 & 4 & 4 & 4 & 4 & 4 \\
\hline Gibraltar* & $\mathrm{Gl}$ & 3 & 3 & 3 & 3 & 3 & 3 & 3 & 3 & 3 & 3 \\
\hline
\end{tabular}




\begin{tabular}{|c|c|c|c|c|c|c|c|c|c|c|c|}
\hline Country & $\begin{array}{l}\text { ISO } \\
\text { code }\end{array}$ & 욤 & ষ্ণ & ¿্ণ & 尺̊ & $\stackrel{\text { ̊̊ }}{\text { ¿ }}$ & ষ্ণ & ஜํํ & 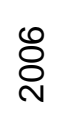 & ᄋ̊̀ & $\stackrel{\infty}{\stackrel{\sim}{~}}$ \\
\hline Greece & GR & 1 & 1 & 1 & 1 & 1 & 1 & 1 & 1 & 1 & 1 \\
\hline Greenland* & GL & 1 & 1 & 1 & 1 & 1 & 1 & 1 & 1 & 1 & 1 \\
\hline Grenada & GD & 2 & 2 & 2 & 2 & 2 & 2 & 2 & 2 & 2 & 2 \\
\hline Guadeloupe* & $\mathrm{GP}$ & 1 & 1 & 1 & 1 & 1 & 1 & 1 & 1 & 1 & 1 \\
\hline Guam* & GU & 2 & 2 & 2 & 2 & 2 & 2 & 2 & 2 & 2 & 2 \\
\hline Guatemala & GT & 4 & 4 & 4 & 4 & 4 & 4 & 4 & 4 & 4 & 4 \\
\hline Guinea & GN & 4 & 4 & 4 & 2 & 2 & 4 & 4 & 4 & 4 & 4 \\
\hline Guinea-Bissau & GW & 1 & 1 & 1 & 1 & 1 & 1 & 1 & 1 & 1 & 1 \\
\hline Guyana & GY & 4 & 4 & 4 & 4 & 4 & 4 & 2 & 2 & 2 & 2 \\
\hline Haiti & HT & 4 & 4 & 4 & 4 & 4 & 4 & 4 & 4 & 4 & 4 \\
\hline Honduras & $\mathrm{HN}$ & 4 & 4 & 4 & 4 & 4 & 4 & 2 & 2 & 2 & 2 \\
\hline Hong Kong & $\mathrm{HK}$ & 2 & 2 & 2 & 2 & 2 & 2 & 2 & 2 & 2 & 2 \\
\hline Hungary & $\mathrm{HU}$ & 4 & 4 & 1 & 1 & 1 & 1 & 1 & 1 & 4 & 4 \\
\hline Iceland & IS & 3 & 4 & 4 & 4 & 4 & 4 & 4 & 4 & 4 & 4 \\
\hline India & IN & 4 & 4 & 4 & 4 & 4 & 4 & 4 & 4 & 4 & 4 \\
\hline Indonesia & ID & 4 & 4 & 4 & 4 & 4 & 4 & 4 & 4 & 4 & 4 \\
\hline Iran & IR & 2 & 2 & 4 & 4 & 4 & 4 & 4 & 3 & 4 & 4 \\
\hline Iraq & IQ & 2 & 2 & 4 & 4 & 4 & 2 & 2 & 4 & 4 & 4 \\
\hline Ireland & IE & 1 & 1 & 1 & 1 & 1 & 1 & 1 & 1 & 1 & 1 \\
\hline Isle of Man* & IM & 3 & 3 & 3 & 3 & 3 & 3 & 3 & 3 & 3 & 3 \\
\hline Israel & IL & 4 & 4 & 4 & 4 & 4 & 4 & 4 & 4 & 4 & 4 \\
\hline Italy & IT & 1 & 1 & 1 & 1 & 1 & 1 & 1 & 1 & 1 & 1 \\
\hline Jamaica & $\mathrm{JM}$ & 4 & 4 & 4 & 4 & 4 & 4 & 4 & 4 & 4 & 4 \\
\hline Japan & JP & 4 & 4 & 4 & 4 & 4 & 4 & 4 & 4 & 4 & 4 \\
\hline Jordan & JO & 2 & 2 & 2 & 2 & 2 & 2 & 2 & 2 & 2 & 2 \\
\hline Kazakhstan & $\mathrm{KZ}$ & 4 & 4 & 4 & 4 & 4 & 4 & 4 & 4 & 2 & 2 \\
\hline Kenya & KE & 4 & 4 & 4 & 4 & 4 & 4 & 4 & 4 & 4 & 4 \\
\hline
\end{tabular}




\begin{tabular}{|c|c|c|c|c|c|c|c|c|c|c|c|}
\hline Country & $\begin{array}{l}\text { ISO } \\
\text { code }\end{array}$ & ஓ & 尺 & ठ̊̀ & ָ̊ & ஜ্ণ & ষ্ণ & 용 & ஜ̊ & & $\begin{array}{l}\infty \\
\stackrel{\sim}{N}\end{array}$ \\
\hline Kiribati & $\mathrm{KI}$ & 3 & 3 & 3 & 3 & 3 & 3 & 3 & 3 & 3 & 3 \\
\hline Korea, DPR* & KP & 2 & 2 & 2 & 4 & 4 & 4 & 4 & 4 & 4 & 4 \\
\hline Korea, Republic & $\mathrm{KR}$ & 4 & 4 & 4 & 4 & 4 & 4 & 4 & 4 & 4 & 4 \\
\hline Kuwait & $\mathrm{KW}$ & 3 & 3 & 3 & 2 & 2 & 2 & 2 & 2 & 3 & 4 \\
\hline Kyrgyz Republic & $K G$ & 4 & 4 & 4 & 4 & 4 & 4 & 4 & 4 & 4 & 4 \\
\hline Laos & LA & 4 & 4 & 4 & 4 & 4 & 4 & 4 & 4 & 4 & 4 \\
\hline Latvia & LV & 3 & 3 & 3 & 3 & 3 & 1 & 1 & 1 & 1 & 1 \\
\hline Lebanon & LB & 2 & 2 & 2 & 2 & 2 & 2 & 2 & 2 & 2 & 2 \\
\hline Lesotho & LS & 3 & 3 & 3 & 3 & 3 & 3 & 3 & 3 & 3 & 3 \\
\hline Liberia & LR & 4 & 4 & 4 & 4 & 4 & 4 & 4 & 4 & 4 & 4 \\
\hline Libya & LY & 3 & 3 & 3 & 3 & 3 & 3 & 3 & 3 & 3 & 3 \\
\hline Liechtenstein* & $\mathrm{LI}$ & 3 & 3 & 3 & 3 & 3 & 3 & 3 & 3 & 3 & 3 \\
\hline Lithuania & LT & 2 & 2 & 1 & 1 & 1 & 1 & 1 & 1 & 1 & 1 \\
\hline Luxembourg & LU & 1 & 1 & 1 & 1 & 1 & 1 & 1 & 1 & 1 & 1 \\
\hline Macao* & MO & 2 & 2 & 2 & 2 & 2 & 2 & 2 & 2 & 2 & 2 \\
\hline Macedonia & MK & 1 & 1 & 1 & 1 & 1 & 1 & 1 & 1 & 1 & 1 \\
\hline Madagascar & MG & 4 & 4 & 4 & 4 & 4 & 4 & 4 & 4 & 4 & 4 \\
\hline Malawi & MW & 4 & 4 & 4 & 4 & 4 & 4 & 4 & 4 & 2 & 2 \\
\hline Malaysia & MY & 2 & 2 & 2 & 2 & 2 & 2 & 4 & 4 & 4 & 4 \\
\hline Maldives & MV & 2 & 2 & 2 & 2 & 2 & 2 & 2 & 2 & 2 & 2 \\
\hline Mali & $\mathrm{ML}$ & 1 & 1 & 1 & 1 & 1 & 1 & 1 & 1 & 1 & 1 \\
\hline Malta & MT & 3 & 3 & 3 & 3 & 3 & 1 & 1 & 1 & 1 & 1 \\
\hline Marshall Islands & $\mathrm{MH}$ & 2 & 2 & 2 & 2 & 2 & 2 & 2 & 2 & 2 & 2 \\
\hline Martinique* & MQ & 1 & 1 & 1 & 1 & 1 & 1 & 1 & 1 & 1 & 1 \\
\hline Mauritania & $\mathrm{MR}$ & 4 & 4 & 4 & 4 & 4 & 4 & 2 & 2 & 4 & 4 \\
\hline Mauritius & $\mathrm{MU}$ & 4 & 4 & 4 & 4 & 4 & 4 & 4 & 4 & 4 & 4 \\
\hline Mayotte* & YT & 1 & 1 & 1 & 1 & 1 & 1 & 1 & 1 & 1 & 1 \\
\hline
\end{tabular}




\begin{tabular}{|c|c|c|c|c|c|c|c|c|c|c|c|}
\hline Country & $\begin{array}{l}\text { ISO } \\
\text { code }\end{array}$ & ஓ & ষ্ণ & ঠ్̊ & ㅇ. & ஜ̊ & ষ্ণ & ஜ̊ & $\begin{array}{l}\stackrel{0}{ } \\
\stackrel{ }{ }\end{array}$ & & $\begin{array}{l}\infty \\
\stackrel{\sim}{N}\end{array}$ \\
\hline Mexico & $\mathrm{MX}$ & 4 & 4 & 4 & 4 & 4 & 4 & 4 & 4 & 4 & 4 \\
\hline Micronesia & FM & 2 & 2 & 2 & 2 & 2 & 2 & 2 & 2 & 2 & 2 \\
\hline Moldova & $\mathrm{MD}$ & 4 & 4 & 4 & 4 & 4 & 4 & 4 & 4 & 4 & 4 \\
\hline Monaco* & MC & 1 & 1 & 1 & 1 & 1 & 1 & 1 & 1 & 1 & 1 \\
\hline Mongolia & MN & 4 & 4 & 4 & 4 & 4 & 4 & 4 & 2 & 2 & 4 \\
\hline Montenegro & $\mathrm{ME}$ & & & & 1 & 1 & 1 & 1 & 1 & 1 & 1 \\
\hline Montserrat* & MS & 2 & 2 & 2 & 2 & 2 & 2 & 2 & 2 & 2 & 2 \\
\hline Morocco & MA & 3 & 3 & 3 & 3 & 3 & 3 & 3 & 3 & 3 & 3 \\
\hline Mozambique & MZ & 4 & 4 & 4 & 4 & 4 & 4 & 4 & 4 & 4 & 4 \\
\hline Myanmar & MM & 3 & 3 & 4 & 4 & 4 & 4 & 4 & 4 & 4 & 4 \\
\hline Namibia & NA & 3 & 3 & 3 & 3 & 3 & 3 & 3 & 3 & 3 & 3 \\
\hline Nauru* & NR & 3 & 3 & 3 & 3 & 3 & 3 & 3 & 3 & 3 & 3 \\
\hline Nepal & NP & 3 & 3 & 3 & 3 & 3 & 3 & 3 & 3 & 3 & 3 \\
\hline Netherlands & $\mathrm{NL}$ & 1 & 1 & 1 & 1 & 1 & 1 & 1 & 1 & 1 & 1 \\
\hline Netherlands Antilles & AN & 2 & 2 & 2 & 2 & 2 & 2 & 2 & 2 & 2 & 2 \\
\hline New Caledonia* & NC & 1 & 1 & 1 & 1 & 1 & 1 & 1 & 1 & 1 & 1 \\
\hline New Zealand & $N Z$ & 4 & 4 & 4 & 4 & 4 & 4 & 4 & 4 & 4 & 4 \\
\hline Nicaragua & $\mathrm{NI}$ & 4 & 4 & 4 & 4 & 4 & 4 & 4 & 4 & 4 & 4 \\
\hline Niger & $\mathrm{NE}$ & 1 & 1 & 1 & 1 & 1 & 1 & 1 & 1 & 1 & 1 \\
\hline Nigeria & NG & 4 & 4 & 4 & 4 & 4 & 4 & 4 & 2 & 4 & 4 \\
\hline Niue* & NU & 3 & 3 & 3 & 3 & 3 & 3 & 3 & 3 & 3 & 3 \\
\hline Northern Mariana Islands* & MP & 2 & 2 & 2 & 2 & 2 & 2 & 2 & 2 & 2 & 2 \\
\hline Norway & NO & 4 & 4 & 4 & 4 & 4 & 4 & 4 & 4 & 4 & 4 \\
\hline Oman & $\mathrm{OM}$ & 2 & 2 & 2 & 2 & 2 & 2 & 2 & 2 & 2 & 2 \\
\hline Pakistan & PK & 2 & 4 & 4 & 4 & 4 & 4 & 2 & 2 & 4 & 4 \\
\hline Palau & PW & 2 & 2 & 2 & 2 & 2 & 2 & 2 & 2 & 2 & 2 \\
\hline Panama & PA & 2 & 2 & 2 & 2 & 2 & 2 & 2 & 2 & 2 & 2 \\
\hline
\end{tabular}




\begin{tabular}{|c|c|c|c|c|c|c|c|c|c|c|c|}
\hline Country & $\begin{array}{l}\text { ISO } \\
\text { code }\end{array}$ & ஓ & ষ্ণ & ઠ్ర & 尺̊ & ஜ̊ & ষ্ণ & 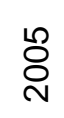 & 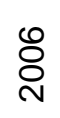 & 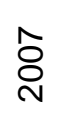 & $\stackrel{\infty}{\stackrel{్}{~}}$ \\
\hline Papua New Guinea & $P G$ & 4 & 4 & 4 & 4 & 4 & 4 & 4 & 4 & 4 & 4 \\
\hline Paraguay & PY & 4 & 4 & 4 & 4 & 4 & 4 & 4 & 4 & 4 & 4 \\
\hline Peru & PE & 4 & 4 & 4 & 4 & 4 & 4 & 4 & 4 & 4 & 4 \\
\hline Philippines & $\mathrm{PH}$ & 4 & 4 & 4 & 4 & 4 & 4 & 4 & 4 & 4 & 4 \\
\hline Pitcairn Islands* & PN & 3 & 3 & 3 & 3 & 3 & 3 & 3 & 3 & 3 & 3 \\
\hline Poland & $\mathrm{PL}$ & 4 & 4 & 4 & 4 & 4 & 4 & 4 & 4 & 4 & 4 \\
\hline Portugal & PT & 1 & 1 & 1 & 1 & 1 & 1 & 1 & 1 & 1 & 1 \\
\hline Puerto Rico* & PR & 2 & 2 & 2 & 2 & 2 & 2 & 2 & 2 & 2 & 2 \\
\hline Qatar & $\mathrm{QA}$ & 2 & 2 & 2 & 2 & 2 & 2 & 2 & 2 & 2 & 2 \\
\hline Réunion* & RE & 1 & 1 & 1 & 1 & 1 & 1 & 1 & 1 & 1 & 1 \\
\hline Romania & RO & 4 & 4 & 4 & 4 & 4 & 4 & 4 & 4 & 4 & 4 \\
\hline Russia & RU & 4 & 4 & 4 & 4 & 4 & 4 & 4 & 4 & 3 & 4 \\
\hline Rwanda & RW & 4 & 4 & 4 & 4 & 4 & 4 & 4 & 2 & 2 & 4 \\
\hline St Helena* & $\mathrm{SH}$ & 3 & 3 & 3 & 3 & 3 & 3 & 3 & 3 & 3 & 3 \\
\hline St Kitts and Nevis & $\mathrm{KN}$ & 2 & 2 & 2 & 2 & 2 & 2 & 2 & 2 & 2 & 2 \\
\hline St Lucia & LC & 2 & 2 & 2 & 2 & 2 & 2 & 2 & 2 & 2 & 2 \\
\hline St Martin and St Barthélemy* & & 1 & 1 & 1 & 1 & 1 & 1 & 1 & 1 & 1 & 1 \\
\hline St Pierre and Miquelon* & PM & 1 & 1 & 1 & 1 & 1 & 1 & 1 & 1 & 1 & 1 \\
\hline St Vincent and the Grenadines & VC & 2 & 2 & 2 & 2 & 2 & 2 & 2 & 2 & 2 & 2 \\
\hline Samoa & WS & 3 & 3 & 3 & 3 & 3 & 3 & 3 & 3 & 3 & 3 \\
\hline San Marino & SM & 1 & 1 & 1 & 1 & 1 & 1 & 1 & 1 & 1 & 1 \\
\hline São Tomé and Príncipe & ST & 4 & 4 & 4 & 4 & 4 & 4 & 4 & 4 & 4 & 1 \\
\hline Saudi Arabia & SA & 2 & 2 & 2 & 2 & 2 & 2 & 2 & 2 & 2 & 2 \\
\hline Senegal & SN & 1 & 1 & 1 & 1 & 1 & 1 & 1 & 1 & 1 & 1 \\
\hline Serbia & RS & & & & 4 & 4 & 4 & 4 & 4 & 4 & 4 \\
\hline Seychelles & SC & 3 & 3 & 3 & 3 & 3 & 2 & 2 & 3 & 2 & 4 \\
\hline Sierra Leone & SL & 4 & 4 & 4 & 4 & 4 & 4 & 4 & 4 & 2 & 4 \\
\hline
\end{tabular}




\begin{tabular}{|c|c|c|c|c|c|c|c|c|c|c|c|}
\hline Country & $\begin{array}{l}\text { ISO } \\
\text { code }\end{array}$ & ஓ & ঃి & ஓ্ণ & ָ̊ & $\stackrel{\overbrace{}}{\check{~}}$ & ষ্ণ & ஜ̊ & ஜ̊ & ঠి & $\begin{array}{l}\infty \\
\stackrel{\varnothing}{~}\end{array}$ \\
\hline Singapore & SG & 4 & 4 & 4 & 4 & 4 & 4 & 4 & 4 & 4 & 4 \\
\hline Slovak Republic & SK & 4 & 4 & 4 & 4 & 4 & 4 & 1 & 1 & 1 & 1 \\
\hline Slovenia & $\mathrm{SI}$ & 4 & 4 & 4 & 4 & 1 & 1 & 1 & 1 & 1 & 1 \\
\hline Solomon Islands & SB & 3 & 3 & 4 & 4 & 4 & 4 & 2 & 2 & 2 & 4 \\
\hline Somalia & so & 4 & 4 & 4 & 4 & 4 & 4 & 4 & 4 & 4 & 4 \\
\hline South Africa & ZA & 4 & 4 & 4 & 4 & 4 & 4 & 4 & 4 & 4 & 4 \\
\hline Spain & ES & 1 & 1 & 1 & 1 & 1 & 1 & 1 & 1 & 1 & 1 \\
\hline Sri Lanka & LK & 4 & 4 & 4 & 4 & 4 & 4 & 4 & 4 & 2 & 4 \\
\hline Sudan & SD & 4 & 4 & 4 & 2 & 4 & 4 & 4 & 4 & 4 & 4 \\
\hline Suriname & $\mathrm{SR}$ & 4 & 2 & 2 & 2 & 2 & 4 & 2 & 2 & 2 & 2 \\
\hline Swaziland & $\mathrm{SZ}$ & 3 & 3 & 3 & 3 & 3 & 3 & 3 & 3 & 3 & 3 \\
\hline Sweden & SE & 4 & 4 & 4 & 4 & 4 & 4 & 4 & 4 & 4 & 4 \\
\hline Switzerland & $\mathrm{CH}$ & 4 & 4 & 4 & 4 & 4 & 4 & 4 & 4 & 4 & 4 \\
\hline Syria & SY & 2 & 2 & 2 & 2 & 2 & 2 & 2 & 2 & 3 & 3 \\
\hline Tajikistan & $\mathrm{TJ}$ & 4 & 4 & 4 & 4 & 4 & 4 & 4 & 4 & 2 & 4 \\
\hline Tanzania & $\mathrm{TZ}$ & 4 & 4 & 4 & 4 & 4 & 4 & 4 & 4 & 4 & 4 \\
\hline Thailand & $\mathrm{TH}$ & 4 & 4 & 4 & 4 & 4 & 4 & 4 & 4 & 4 & 4 \\
\hline Timor-Leste & TL & & & & 2 & 2 & 2 & 2 & 2 & 2 & 2 \\
\hline Togo & TG & 1 & 1 & 1 & 1 & 1 & 1 & 1 & 1 & 1 & 1 \\
\hline Tokelau* & TK & 3 & 3 & 3 & 3 & 3 & 3 & 3 & 3 & 3 & 3 \\
\hline Tonga & TO & 3 & 3 & 3 & 3 & 3 & 3 & 3 & 3 & 3 & 3 \\
\hline Trinidad and Tobago & TT & 2 & 2 & 4 & 4 & 4 & 2 & 2 & 2 & 2 & 2 \\
\hline Tunisia & TN & 4 & 4 & 4 & 4 & 4 & 4 & 4 & 4 & 3 & 4 \\
\hline Turkey & TR & 4 & 4 & 4 & 4 & 4 & 4 & 4 & 4 & 4 & 4 \\
\hline Turkmenistan & TM & 2 & 2 & 2 & 2 & 2 & 2 & 2 & 2 & 2 & 2 \\
\hline Turks and Caicos Islands* & TC & 2 & 2 & 2 & 2 & 2 & 2 & 2 & 2 & 2 & 2 \\
\hline Tuvalu* & TV & 3 & 3 & 3 & 3 & 3 & 3 & 3 & 3 & 3 & 3 \\
\hline
\end{tabular}




\begin{tabular}{|c|c|c|c|c|c|c|c|c|c|c|c|}
\hline Country & $\begin{array}{l}\text { ISO } \\
\text { code }\end{array}$ & ஓ্ & ষ্ণ & ठ্ণ & ్ָరి & ஜ্ণ & ষ্ণ & ஜ̊ & ஜ & ¿ి & $\begin{array}{l}\infty \\
\stackrel{D}{N}\end{array}$ \\
\hline Uganda & UG & 4 & 4 & 4 & 4 & 4 & 4 & 4 & 4 & 4 & 4 \\
\hline Ukraine & UA & 4 & 4 & 4 & 2 & 2 & 2 & 2 & 2 & 4 & 4 \\
\hline United Arab Emirates & $\mathrm{AE}$ & 2 & 2 & 2 & 2 & 2 & 2 & 2 & 2 & 2 & 2 \\
\hline United Kingdom & GB & 4 & 4 & 4 & 4 & 4 & 4 & 4 & 4 & 4 & 4 \\
\hline Uruguay & UY & 4 & 4 & 4 & 4 & 4 & 4 & 4 & 4 & 4 & 4 \\
\hline US Virgin Islands* & VI & 2 & 2 & 2 & 2 & 2 & 2 & 2 & 2 & 2 & 2 \\
\hline Uzbekistan & UZ & 4 & 4 & 4 & 4 & 4 & 4 & 4 & 2 & 4 & 4 \\
\hline Vanuatu & VU & 3 & 3 & 3 & 3 & 3 & 3 & 3 & 3 & 4 & 4 \\
\hline Venezuela & VE & 4 & 4 & 4 & 2 & 2 & 2 & 2 & 2 & 2 & 2 \\
\hline Vietnam & VN & 2 & 2 & 4 & 4 & 4 & 4 & 2 & 2 & 2 & 4 \\
\hline Wallis and Futuna* & WF & 1 & 1 & 1 & 1 & 1 & 1 & 1 & 1 & 1 & 1 \\
\hline Yemen & YE & 4 & 4 & 4 & 4 & 4 & 4 & 4 & 2 & 2 & 2 \\
\hline Yugoslavia & YU & & 4 & 4 & & & & & & & \\
\hline Zambia & ZM & 4 & 4 & 4 & 4 & 4 & 4 & 4 & 4 & 4 & 4 \\
\hline Zimbabwe & ZW & 2 & 4 & 2 & 2 & 2 & 4 & 2 & 2 & 2 & 4 \\
\hline
\end{tabular}

Notes:

The numbers 1 to 3 indicate that the country's exchange rate regime is a peg which includes the IMF categories "no separate legal tender", "currency board", "conventional peg", "stabilized arrangement", and "pegged exchange rate within horizontal bands". The number 1 indicates a country that belongs to the euro bloc and comprises the IMF categories "country participates in the euro area", "country participates in ERM II", and "flexibility is limited vis-à-vis the euro". The number $\mathbf{2}$ denotes a country belonging to the US dollar bloc (IMF category "flexibility is limited vis-à-vis the U.S. dollar"). The number 3 denotes a peg to another currency or basket and comprises the IMF categories "flexibility is limited vis-à-vis another single currency", "flexibility is limited vis-à-vis the SDR", and "flexibility is limited vis-à-vis another basket of currencies". The number 4 indicates that the country's exchange rate is flexible in a broad sense; it comprises the IMF categories "free floating" (except countries participating in the euro area), "floating", "other managed arrangement", "crawl-like arrangement", and "crawling peg". Usually, the data are taken from the IMF Annual Report on Exchange Arrangements and Exchange Restrictions. Data from year $t$ 's volume often refer to the end of the previous year $t-1$, and are therefore generally assigned to $t-1$. A star * indicates that the IMF does not provide data on the country or territory in question; in these cases, the data are taken from various issues of Deutsche Bundesbank, Exchange Rate Statistics, Statistical Supplement to the Monthly Report 5. This source has also been used in instances where the IMF's data were inconclusive, for example, if the exchange rate regime was classified but no information on the anchor currency was given. The USA and Germany being effectively the economies to which the other members of the US dollar bloc and the euro bloc, respectively, have pegged their currencies, are not included in the Table. 


\section{Appendix 2: Data sources for explanatory variables}

Each of the following data have been used for all countries and territories available.

Real GDP: Series “GDP, PPP (constant 2005 international \$)”; annual data; source: World Bank, WDI 2010.

Real per capita GDP: Series “GDP per capita, PPP (constant 2005 international \$)”; annual data; source: WDI 2010.

Trade openness: Series "Exports of goods and services (\% of GDP)” plus series “Imports of goods and services (\% of GDP)”; annual data; source: WDI 2010.

Population: Series “Population, total”; annual data; source: WDI 2010.

Trade with the US dollar (euro) bloc as a fraction of total trade: For each year, two full DOTS cross-country matrices have been downloaded, one showing the exports of each country to all destination countries, and the other showing the (c.i.f.) imports of each country from all origin countries; annual data; source: IMF, DOTS 2010.

Distance: Great circle distance between a given country’s capital and Washington, DC, Frankfurt am Main or Beijing measured in kilometres as computed on the website http://www.timeanddate.com/worldclock/distance.html.

Share of net oil exports in total exports: Series "Oil trade balance”, W...TBO, divided by series "Value of exports of goods \& services”, W...TX; annual data; source: IMF, WEO 2010.

Dummy for present or former euro bloc colony: CIA, World Fact Book, https://www.cia.gov/library/publications/the-world-factbook/index.html. 
Appendix 3: Nested logit model for exchange rate regime and anchor currency choice: results for the years 2000-2007

\begin{tabular}{|c|c|c|c|c|c|c|c|c|c|}
\hline & & 2007 & 2006 & 2005 & 2004 & 2003 & 2002 & 2001 & 2000 \\
\hline \multirow[t]{4}{*}{$\mathbf{z}$} & GDP & $-0.26^{\star \star \star}$ & $-0.25^{\star \star \star}$ & $-0.33^{\star \star \star}$ & $-0.43^{\star \star \star}$ & $-0.35^{\star \star \star}$ & $-0.28^{\star \star \star}$ & $-0.33^{\star \star \star}$ & $-0.34^{\star \star \star}$ \\
\hline & & $(-4.19)$ & $(-3.99)$ & $(-4.85)$ & $(-5.53)$ & $(-4.96)$ & $(-4.33)$ & $(-4.81)$ & $(-4.84)$ \\
\hline & GDP & $0.67^{\star \star \star}$ & $0.64^{\star \star \star}$ & $0.82^{\star \star \star}$ & $1.07^{\star \star \star}$ & 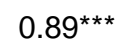 & $0.72^{\star \star \star}$ & $0.82^{\star \star \star}$ & $0.86^{\star \star \star}$ \\
\hline & per capita & $(4.04)$ & (3.88) & $(4.63)$ & $(5.29)$ & $(4.79)$ & $(4.20)$ & $(4.55)$ & (4.65) \\
\hline \multirow[t]{8}{*}{$x_{1}$} & Oil exports & -0.44 & 0.006 & 0.15 & -0.79 & -0.58 & -0.40 & $-1.03^{\star}$ & -0.86 \\
\hline & & $(-0.91)$ & $(0.01)$ & $(0.25)$ & $(-1.48)$ & $(-1.07)$ & $(-0.90)$ & $(-1.73)$ & $(-1.54)$ \\
\hline & Dist(Fra) & $-0.14^{\star \star}$ & $-0.14^{\star}$ & $-0.15^{\star \star}$ & $-0.16^{\star \star}$ & $-0.18^{\star \star}$ & $-0.13^{\star}$ & $-0.15^{\star \star}$ & $-0.15^{\star \star}$ \\
\hline & & $(-2.10)$ & $(-1.94)$ & $(-2.29)$ & $(-2.32)$ & $(-2.29)$ & $(-1.71)$ & $(-2.35)$ & $(-2.40)$ \\
\hline & Trade(EUR) & $3.24^{\star \star}$ & $3.18^{\star \star}$ & $3.45^{\star \star \star}$ & $3.30^{\star \star \star}$ & $3.24^{\star \star}$ & $2.38^{\star}$ & $3.28^{\star \star \star}$ & $3.03^{\star \star \star}$ \\
\hline & & $(2.36)$ & (2.19) & $(2.84)$ & $(2.80)$ & $(2.41)$ & $(1.76)$ & $(2.68)$ & (2.69) \\
\hline & Col(EUR) & $1.42^{\star \star}$ & $1.29 *$ & $1.70^{\star \star \star}$ & $2.33^{\star \star \star}$ & $1.72^{\star \star \star}$ & $1.26^{*}$ & $1.63^{\star \star \star}$ & $1.77^{\star \star \star}$ \\
\hline & & $(2.22)$ & (1.93) & $(2.77)$ & (3.68) & $(2.57)$ & $(1.87)$ & $(2.71)$ & $(2.72)$ \\
\hline \multirow[t]{6}{*}{$x_{2}$} & Oil exports & -0.20 & 0.14 & 0.11 & 0.18 & 0.16 & 0.12 & 0.009 & 0.31 \\
\hline & & $(-0.60)$ & $(0.31)$ & $(0.26)$ & $(0.53)$ & $(0.43)$ & $(0.40)$ & $(0.03)$ & $(0.88)$ \\
\hline & Dist(Wash) & 0.011 & -0.003 & -0.010 & -0.037 & $-0.042^{*}$ & $-0.036^{\star}$ & -0.030 & $-0.039 *$ \\
\hline & & $(0.62)$ & $(-0.15)$ & $(-0.42)$ & $(-1.63)$ & $(-1.93)$ & $(-1.89)$ & $(-1.26)$ & $(-1.70)$ \\
\hline & Trade(USD) & $1.37^{*}$ & $1.90^{\star *}$ & $1.99^{\star \star}$ & $1.92^{\star \star}$ & 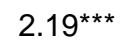 & $1.92^{\star \star}$ & $1.84^{\star \star}$ & $1.74^{\star *}$ \\
\hline & & (1.85) & $(2.08)$ & $(2.47)$ & $(2.44)$ & $(2.80)$ & $(2.41)$ & (2.38) & $(2.46)$ \\
\hline \multicolumn{2}{|l|}{$\tau$} & 0.29 & 0.31 & 0.35 & 0.22 & 0.25 & 0.19 & 0.30 & 0.29 \\
\hline \multicolumn{2}{|c|}{$\mathrm{p}(\tau=1)$} & 0.004 & 0.006 & 0.004 & 0.0002 & 0.001 & 0.0004 & 0.002 & 0.002 \\
\hline \multicolumn{2}{|c|}{$p\left(\operatorname{oil}\left(\mathbf{x}_{1}\right)=\operatorname{oil}\left(\mathbf{x}_{2}\right)\right)$} & 0.61 & 0.79 & 0.95 & 0.07 & 0.21 & 0.32 & 0.09 & 0.06 \\
\hline \multicolumn{2}{|c|}{$N_{1}$ (peg EUR) } & 40 & 40 & 40 & 38 & 36 & 35 & 35 & 33 \\
\hline \multicolumn{2}{|c|}{$N_{2}($ peg USD) } & 39 & 43 & 39 & 28 & 29 & 31 & 27 & 30 \\
\hline \multicolumn{2}{|c|}{$N_{3}$ (peg other) } & 11 & 10 & 8 & 8 & 11 & 11 & 12 & 14 \\
\hline \multicolumn{2}{|c|}{$N_{4}$ (float) } & 74 & 72 & 80 & 90 & 88 & 87 & 89 & 85 \\
\hline
\end{tabular}

Variables and coefficients as defined in chapters 3 and 4; $z$-values in parenthesis; *** significant at $1 \%$ level, ** significant at 5\% level, * significant at $10 \%$ level. " $\mathrm{p}(\tau=1)$ ” gives $p$-values of an LR test on $\tau=$ 1 ; " $\mathrm{p}\left(\operatorname{oil}\left(\mathbf{x}_{1}\right)=\operatorname{oil}\left(\mathbf{x}_{2}\right)\right)$ " gives $p$-values of a Wald test on the equality of the two oil export parameters, the one in the US dollar bloc and the one in the euro bloc equation. 
Table 1: Nested logit model for exchange rate regime and anchor currency choice

\begin{tabular}{|c|c|c|c|c|}
\hline & & 2008 & 1999 & Pool \\
\hline \multirow[t]{4}{*}{$\mathbf{z}$} & GDP & $-0.334^{\star * \star}$ & $-0.299^{\star \star \star}$ & 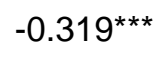 \\
\hline & & $(-4.38)$ & $(-4.50)$ & $(-5.17)$ \\
\hline & GDP per capita & $0.771^{\star \star \star}$ & $0.771^{\star \star \star}$ & 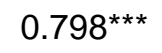 \\
\hline & & (3.88) & $(4.30)$ & $(4.92)$ \\
\hline \multirow[t]{8}{*}{$x_{1}$} & Oil export share & 0.038 & $-0.946^{\star}$ & -0.496 \\
\hline & & $(0.04)$ & $(-1.73)$ & $(-0.64)$ \\
\hline & Distance(Frankfurt) & $-0.216^{\star \star *}$ & $-0.153^{\star *}$ & $-0.160^{\star \star *}$ \\
\hline & & $(-2.60)$ & $(-2.23)$ & $(-2.60)$ \\
\hline & Trade(EUR) share & $5.15^{\star \star \star}$ & $2.80 * \star$ & $3.38^{\star \star \star}$ \\
\hline & & (3.52) & $(2.44)$ & $(2.77)$ \\
\hline & Colony (EUR) & $2.94^{\star \star \star}$ & $1.64^{\star \star \star}$ & $1.78^{\star \star \star}$ \\
\hline & & $(3.96)$ & $(2.71)$ & $(2.62)$ \\
\hline \multirow[t]{6}{*}{$x_{2}$} & Oil export share & $1.50^{\star}$ & 0.110 & 0.199 \\
\hline & & $(1.78)$ & $(0.36)$ & $(0.49)$ \\
\hline & Distance(Washington) & -0.033 & -0.025 & -0.020 \\
\hline & & $(-0.94)$ & $(-1.35)$ & $(-1.23)$ \\
\hline & Trade(USD) share & 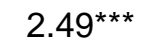 & $1.30^{* *}$ & $1.77^{\star \star \star}$ \\
\hline & & $(2.59)$ & $(2.20)$ & $(3.55)$ \\
\hline \multicolumn{2}{|l|}{$\tau$} & 0.487 & 0.249 & 0.326 \\
\hline \multicolumn{2}{|c|}{$\mathrm{p}(\tau=1)$} & 0.029 & 0.0007 & \\
\hline \multicolumn{2}{|c|}{$\mathrm{p}\left(\mathrm{oil}\left(\mathrm{x}_{1}\right)=\operatorname{oil}\left(\mathrm{x}_{2}\right)\right)$} & 0.056 & 0.069 & 0.293 \\
\hline \multicolumn{2}{|c|}{$N_{1}($ peg EUR) } & 39 & 33 & 369 \\
\hline \multicolumn{2}{|c|}{$N_{2}($ peg USD) } & 29 & 30 & 325 \\
\hline \multicolumn{2}{|c|}{$N_{3}$ (peg other) } & 8 & 15 & 108 \\
\hline \multicolumn{2}{|c|}{$N_{4}$ (float) } & 81 & 82 & 828 \\
\hline
\end{tabular}

Variables and coefficients as defined in chapters 3 and $4 ; z$-values in parenthesis; *** significant at $1 \%$ level, ** significant at 5\% level, * significant at $10 \%$ level. "Pool" = data for 1999-2008 is pooled; in the pooled estimation, computation of robust standard errors is based on country clusters; " $\mathrm{p}(\tau=1)$ " gives $p$ values of an LR test on $\tau=1$; "p $\left.\operatorname{oil}\left(\mathbf{x}_{1}\right)=\operatorname{oil}\left(\mathbf{x}_{2}\right)\right)$ " gives $p$-values of a Wald test on the equality of the two oil export parameters, the one in the US dollar bloc and the one in the euro bloc equation. Results for the years 2000-2007 are shown in Appendix 3. 
Table 2: Estimated average marginal effects on the probability of choosing a given exchange rate regime or anchor currency; percentage points

\begin{tabular}{|c|c|c|c|c|}
\hline & & 2008 & 1999 & Pool \\
\hline GDP & peg EUR $\left(p_{i 1}\right)$ & -2.41 & -2.21 & -2.40 \\
\hline \multirow[t]{3}{*}{ (increase by $1 \%$ ) } & peg USD $\left(p_{i 2}\right)$ & -2.94 & -2.69 & -3.01 \\
\hline & peg other $\left(p_{i 3}\right)$ & -0.94 & -1.28 & -1.02 \\
\hline & float $\left(p_{i 4}\right)$ & 6.28 & 6.19 & 6.43 \\
\hline GDP per capita & peg EUR $\left(p_{i 1}\right)$ & 5.56 & 5.71 & 6.00 \\
\hline \multirow[t]{3}{*}{ (increase by $1 \%$ ) } & peg USD $\left(p_{i 2}\right)$ & 6.79 & 6.94 & 7.52 \\
\hline & peg other $\left(p_{i 3}\right)$ & 2.17 & 3.31 & 2.56 \\
\hline & float $\left(p_{i 4}\right)$ & -14.52 & -15.96 & -16.08 \\
\hline Distance(Frankfurt) & peg EUR $\left(p_{i 1}\right)$ & -2.51 & -2.63 & -2.42 \\
\hline \multirow[t]{3}{*}{ (increase by $1 \%$ ) } & peg USD $\left(p_{i 2}\right)$ & 0.62 & 0.74 & 0.73 \\
\hline & peg other $\left(p_{i 3}\right)$ & 0.34 & 0.76 & 0.49 \\
\hline & float $\left(p_{i 4}\right)$ & 1.56 & 1.13 & 1.20 \\
\hline Distance(Washington) & peg EUR $\left(p_{i 1}\right)$ & 0.10 & 0.12 & 0.09 \\
\hline \multirow[t]{3}{*}{ (increase by $1 \%$ ) } & peg USD $\left(p_{i 2}\right)$ & -0.52 & -0.72 & -0.45 \\
\hline & peg other $\left(p_{i 3}\right)$ & 0.13 & 0.38 & 0.18 \\
\hline & float $\left(p_{i 4}\right)$ & 0.29 & 0.22 & 0.18 \\
\hline Oil export share & peg EUR $\left(p_{i 1}\right)$ & -0.04 & -0.17 & -0.08 \\
\hline \multirow[t]{3}{*}{ (increase by $1 P P$ ) } & peg USD $\left(p_{i 2}\right)$ & 0.23 & 0.08 & 0.07 \\
\hline & peg other $\left(p_{i 3}\right)$ & -0.06 & 0.03 & 0 \\
\hline & float $\left(p_{i 4}\right)$ & -0.13 & 0.06 & 0.02 \\
\hline Trade(EUR) share & peg EUR $\left(p_{i 1}\right)$ & 0.60 & 0.48 & 0.51 \\
\hline \multirow[t]{3}{*}{ (increase by 1 PP) } & peg USD $\left(p_{i 2}\right)$ & -0.15 & -0.14 & -0.16 \\
\hline & peg other $\left(p_{i 3}\right)$ & -0.08 & -0.14 & -0.10 \\
\hline & float $\left(p_{i 4}\right)$ & -0.37 & -0.21 & -0.25 \\
\hline Trade(USD) share & peg EUR $\left(p_{i 1}\right)$ & -0.07 & -0.06 & -0.08 \\
\hline \multirow[t]{3}{*}{ (increase by $1 P P$ ) } & peg USD $\left(p_{i 2}\right)$ & 0.39 & 0.38 & 0.41 \\
\hline & peg other $\left(p_{i 3}\right)$ & -0.10 & -0.20 & -0.16 \\
\hline & float $\left(p_{i 4}\right)$ & -0.22 & -0.12 & -0.17 \\
\hline Colony (EUR) & peg EUR $\left(p_{i 1}\right)$ & 44.57 & 35.96 & 33.68 \\
\hline ("colony" instead of & peg USD $\left(p_{i 2}\right)$ & -13.42 & -12.49 & -12.13 \\
\hline \multirow[t]{2}{*}{ "no colony") } & peg other $\left(p_{i 3}\right)$ & -4.52 & -7.52 & -5.19 \\
\hline & float $\left(p_{i 4}\right)$ & -26.62 & -15.96 & -16.35 \\
\hline
\end{tabular}

“Pool” = data for 1999-2008 is pooled; $P P=$ percentage point. 
Table 3: Nested logit model for exchange rate regime and anchor currency choice: US dollar as "anchor of last resort"?

\begin{tabular}{|c|c|c|c|}
\hline & & (1) & (2) \\
\hline \multirow[t]{4}{*}{$\mathbf{z}$} & GDP & $-0.495^{\star \star \star}$ & $-0.276^{\star \star \star}$ \\
\hline & & $(-4.19)$ & $(-4.42)$ \\
\hline & GDP per capita & $1.23^{\star \star \star}$ & $0.657^{\star \star *}$ \\
\hline & & $(4.02)$ & $(3.76)$ \\
\hline \multirow[t]{8}{*}{$x_{1}$} & Oil export share & -1.17 & -0.914 \\
\hline & & $(-1.21)$ & $(-1.25)$ \\
\hline & Distance(Frankfurt) & $-0.157^{\star}$ & $-0.159 \star *$ \\
\hline & & $(-1.94)$ & $(-2.39)$ \\
\hline & Trade(EUR) share & $3.60 * *$ & $3.52^{\star \star}$ \\
\hline & & $(1.98)$ & $(2.53)$ \\
\hline & Colony (EUR) & $3.23^{\star \star *}$ & $1.98^{\star \star \star}$ \\
\hline & & $(3.72)$ & $(3.45)$ \\
\hline \multirow[t]{6}{*}{$x_{2}$} & Oil export share & 0.638 & 0.164 \\
\hline & & $(0.92)$ & $(0.37)$ \\
\hline & Distance(Washington) & $-0.079^{\star \star \star}$ & -0.020 \\
\hline & & $(-2.87)$ & $(-1.17)$ \\
\hline & Trade(USD) share & $2.89 * \star \star$ & $1.04^{\star \star}$ \\
\hline & & (3.23) & $(2.46)$ \\
\hline \multicolumn{2}{|l|}{$\tau$} & 0.405 & 0.360 \\
\hline \multicolumn{2}{|c|}{$\mathrm{p}\left(\mathrm{oil}\left(\mathbf{x}_{1}\right)=\operatorname{oil}\left(\mathbf{x}_{2}\right)\right)$} & 0.023 & 0.065 \\
\hline \multicolumn{2}{|c|}{$N_{1}$ (peg EUR) } & 361 & 369 \\
\hline \multicolumn{2}{|c|}{$N_{2}($ peg USD) } & 176 & 149 \\
\hline \multicolumn{2}{|c|}{$N_{3}$ (peg other) } & 90 & 108 \\
\hline \multicolumn{2}{|c|}{$N_{4}$ (float) } & 609 & 828 \\
\hline
\end{tabular}

Variables and coefficients as defined in chapters 3 and 4 ; $z$-values in parenthesis; *** significant at $1 \%$ level, ** significant at $5 \%$ level, * significant at $10 \%$ level. Computation of robust standard errors is based on country clusters; " $\mathrm{p}\left(\operatorname{oil}\left(\mathbf{x}_{1}\right)=\operatorname{oil}\left(\mathbf{x}_{2}\right)\right)$ " gives $p$-values of a Wald test on the equality of the two oil export parameters, the one in the US dollar bloc and the one in the euro bloc equation. (1) excludes from the sample all those countries that pegged only temporarily to the US dollar. (2) excludes from the sample all those countries that pegged permanently to the US dollar. 
Table 4: Nested logit model for exchange rate regime and anchor currency choice: Check for endogeneity of explanatory variables

\begin{tabular}{|c|c|c|c|c|}
\hline & & (1) & (2) & (3) \\
\hline \multirow[t]{4}{*}{$\mathbf{z}$} & GDP & $-0.319^{\star \star \star}$ & -0.072 & -0.214 \\
\hline & & $(-5.15)$ & $(-0.67)$ & $(-1.29)$ \\
\hline & GDP per capita & $0.797^{\star \star \star}$ & -0.271 & -0.101 \\
\hline & & $(4.91)$ & $(-1.13)$ & $(-0.35)$ \\
\hline \multirow[t]{8}{*}{$x_{1}$} & Oil export share & -0.518 & & \\
\hline & & $(-0.67)$ & & \\
\hline & Distance(Frankfurt) & $-0.161^{\star \star \star}$ & -0.887 & -1.06 \\
\hline & & $(-2.60)$ & $(-1.58)$ & $(-1.48)$ \\
\hline & Trade(EUR) share & $3.39^{* \star \star}$ & $15.1^{\star *}$ & $18.6^{\star *}$ \\
\hline & & $(2.76)$ & $(2.18)$ & $(2.18)$ \\
\hline & Colony (EUR) & $1.74^{\star \star \star}$ & & \\
\hline & & $(2.58)$ & & \\
\hline \multirow[t]{6}{*}{$x_{2}$} & Oil export share & 0.203 & $3.43^{\star \star}$ & $4.59 \star \star \star x$ \\
\hline & & $(0.50)$ & $(2.35)$ & $(2.71)$ \\
\hline & Distance(Washington) & -0.024 & $0.338^{*}$ & $0.484^{*}$ \\
\hline & & $(-1.48)$ & $(1.93)$ & $(1.74)$ \\
\hline & Trade(USD) share & $1.90^{\star \star \star}$ & 0.147 & 0.178 \\
\hline & & $(3.65)$ & $(0.11)$ & $(0.10)$ \\
\hline \multicolumn{2}{|l|}{$\tau$} & 0.326 & 1.45 & 2.36 \\
\hline \multicolumn{2}{|c|}{$p\left(\operatorname{oil}\left(\mathbf{x}_{1}\right)=\operatorname{oil}\left(\mathbf{x}_{2}\right)\right)$} & 0.281 & & \\
\hline \multicolumn{2}{|c|}{$N_{1}($ peg EUR) } & 368 & 5 & 5 \\
\hline \multicolumn{2}{|c|}{$N_{2}$ (peg USD) } & 325 & 33 & 22 \\
\hline \multicolumn{2}{|c|}{$N_{3}$ (peg other) } & 108 & 3 & 3 \\
\hline \multicolumn{2}{|c|}{$N_{4}$ (float) } & 828 & 55 & 55 \\
\hline
\end{tabular}

Variables and coefficients as defined in chapters 3 and 4 ; $z$-values in parenthesis; *** significant at $1 \%$ level, ** significant at 5\% level, * significant at 10\% level; in model (1), computation of robust standard errors is based on country clusters; " $\mathrm{p}\left(\operatorname{oil}\left(\mathbf{x}_{1}\right)=\operatorname{oil}\left(\mathbf{x}_{2}\right)\right)$ " gives $p$-values of a Wald test on the equality of the two oil export parameters, the one in the US dollar bloc and the one in the euro bloc equation. (1) Pooled estimation, trade shares lagged by 1 year. (2) Sample restricted to permanent floaters in 2004 and countries that have just switched from a float to a peg. (3) as (2) but re-pegging countries excluded from the sample. 
Table 5: The path to a currency bloc equilibrium based on the estimates for 2008

\begin{tabular}{|c|c|c|c|c|}
\hline Round & Country & Current regime & New regime & $p$-value in $\%$ \\
\hline 1 & Malawi & peg(USD) & float & 0.0002 \\
\hline 2 & China & peg(USD) & float & 0.0002 \\
\hline 3 & Bangladesh & peg(USD) & float & 0.0002 \\
\hline 4 & Yemen & peg(USD) & float & 0.03 \\
\hline 5 & Jordan & $\operatorname{peg}($ USD) & float & 0.09 \\
\hline 6 & Switzerland & float & peg(EUR) & 0.16 \\
\hline 7 & Iceland & float & peg(EUR) & 0.36 \\
\hline 8 & Suriname & peg(USD) & peg(EUR) & 0.35 \\
\hline 9 & Czech Republic & float & peg(EUR) & 0.52 \\
\hline 10 & Croatia & float & $\operatorname{peg}(E U R)$ & 0.45 \\
\hline 11 & Albania & float & peg(EUR) & 1.05 \\
\hline 12 & Lebanon & peg(USD) & float & 1.71 \\
\hline 13 & Algeria & float & $\operatorname{peg}(E U R)$ & 1.97 \\
\hline 14 & Turkmenistan & peg(USD) & float & 2.15 \\
\hline 15 & Djibouti & peg(USD) & peg(EUR) & 2.82 \\
\hline 16 & Hungary & float & peg(EUR) & 2.86 \\
\hline 17 & Serbia & float & peg(EUR) & 1.26 \\
\hline
\end{tabular}

The path to the equilibrium is computed according to the algorithm described in section 6.1. The "new regime" is the regime that has been estimated as providing the highest deterministic utility based on a currency bloc constellation as given in the corresponding round of the algorithm. The $p$-value refers to a country-specific Wald test on the equality of the estimated deterministic utilities of the current and the "new" regimes. Only those cases are considered in which the estimated deterministic utility of the new regime is higher than that of the current regime. 
Table 6: The path to a currency bloc equilibrium based on the estimates for the pool

\begin{tabular}{|c|c|c|c|c|}
\hline Round & Country & Current regime & New regime & $p$-value in $\%$ \\
\hline 1 & Zimbabwe & peg(USD) & float & 0.00003 \\
\hline 2 & Malawi & peg(USD) & float & 0.00009 \\
\hline 3 & Bangladesh & peg(USD) & float & 0.0001 \\
\hline 4 & China & peg(USD) & float & 0.0003 \\
\hline 5 & Yemen & peg(USD) & float & 0.0002 \\
\hline 6 & Switzerland & float & peg(EUR) & 0.04 \\
\hline 7 & Iceland & float & peg(EUR) & 0.03 \\
\hline 8 & Seychelles & float & peg(USD) & 0.18 \\
\hline 9 & Kazakhstan & peg(USD) & float & 0.19 \\
\hline 10 & Croatia & float & $\operatorname{peg}(E U R)$ & 0.31 \\
\hline 11 & Czech Republic & float & peg(EUR) & 0.30 \\
\hline 12 & Turkmenistan & peg(USD) & float & 0.31 \\
\hline 13 & Chad & peg(EUR) & float & 1.46 \\
\hline 14 & Albania & float & peg(EUR) & 1.63 \\
\hline 15 & Hungary & float & peg(EUR) & 1.76 \\
\hline 16 & Sweden & float & peg(EUR) & 1.82 \\
\hline 17 & Norway & float & peg(EUR) & 0.96 \\
\hline 18 & Angola & peg(USD) & float & 1.90 \\
\hline 19 & Serbia & float & peg(EUR) & 2.14 \\
\hline 20 & Jordan & peg(USD) & float & 2.90 \\
\hline 21 & Jamaica & float & peg(USD) & 3.90 \\
\hline
\end{tabular}

The path to the equilibrium is computed according to the algorithm described in section 6.1. The "new regime" is the regime that has been estimated as providing the highest deterministic utility based on a currency bloc constellation as given in the corresponding round of the algorithm. The $p$-value refers to a country-specific Wald test on the equality of the estimated deterministic utilities of the current and the "new" regimes. Only those cases are considered in which the estimated deterministic utility of the new regime is higher than that of the current regime. Concerning the result for Zimbabwe in round 1, $c f$ footnote 12 in section 5.2 . 
Countries whose currency's flexibility is limited vis-a-vis the US dollar

Countries whose currency's flexibility is limited vis-a-vis the euro

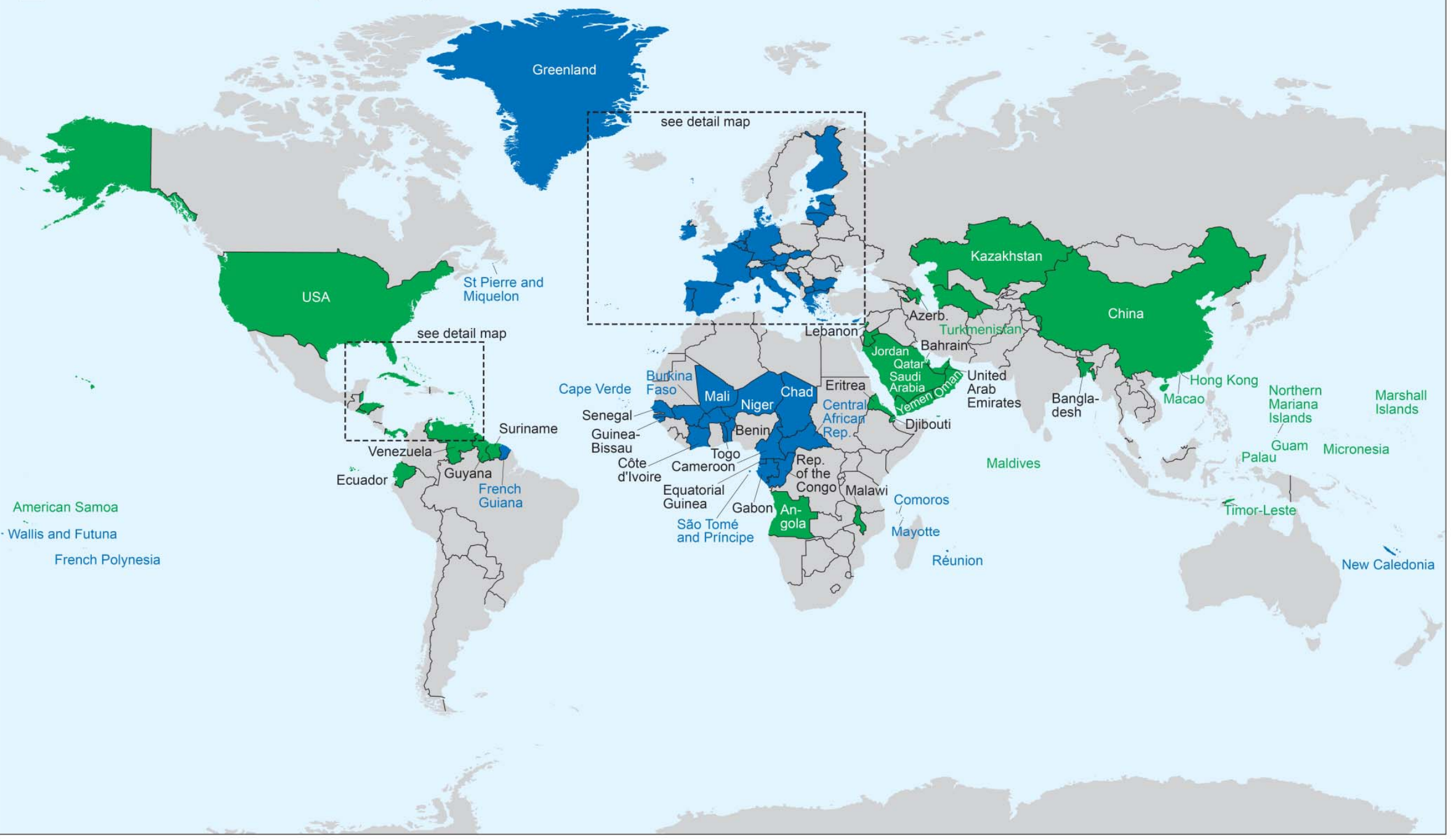


Figure 2: Map of the two major currency blocs in 2008, Europe

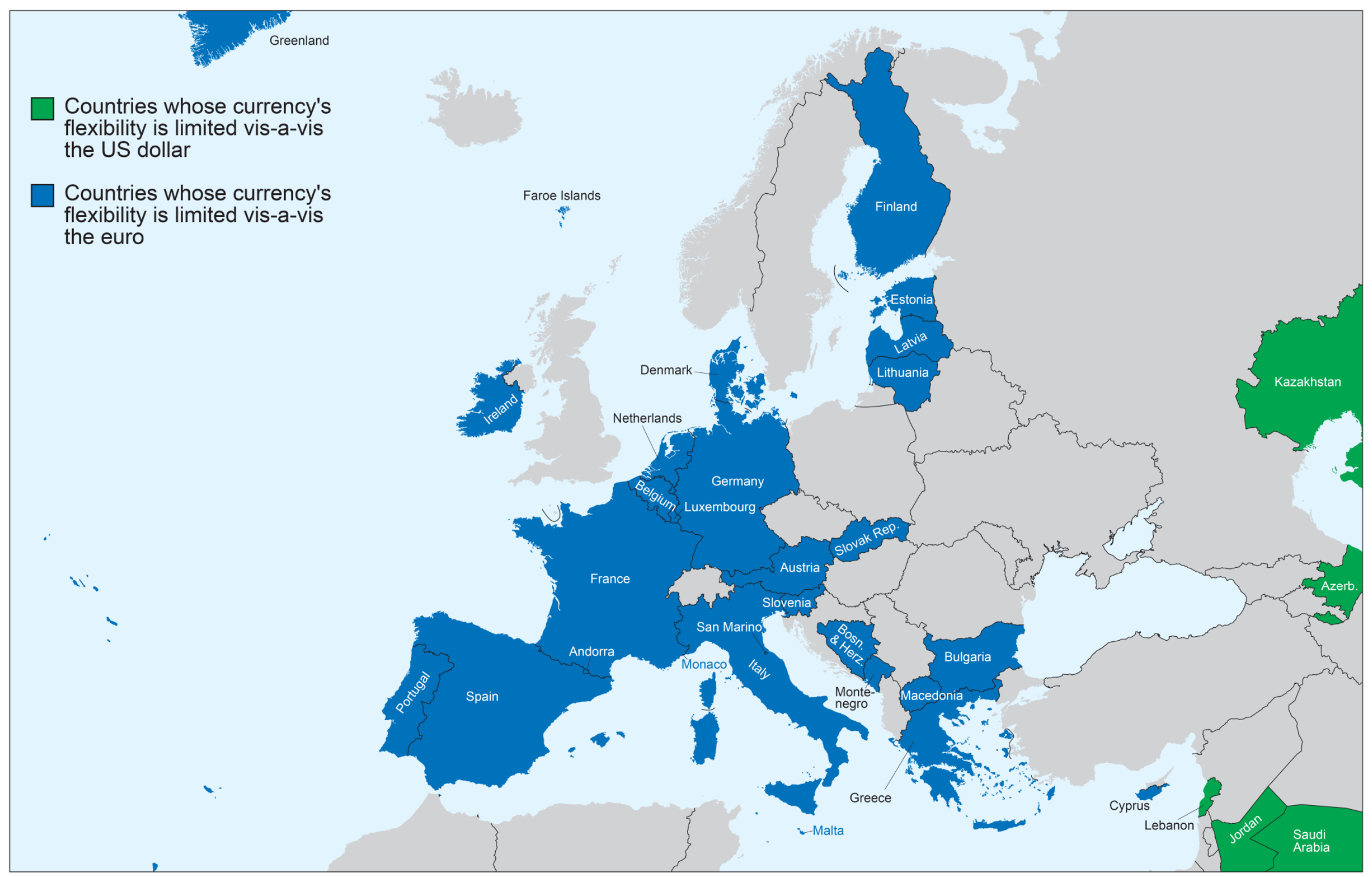


Figure 3: Map of the two major currency blocs in 2008, West Indies

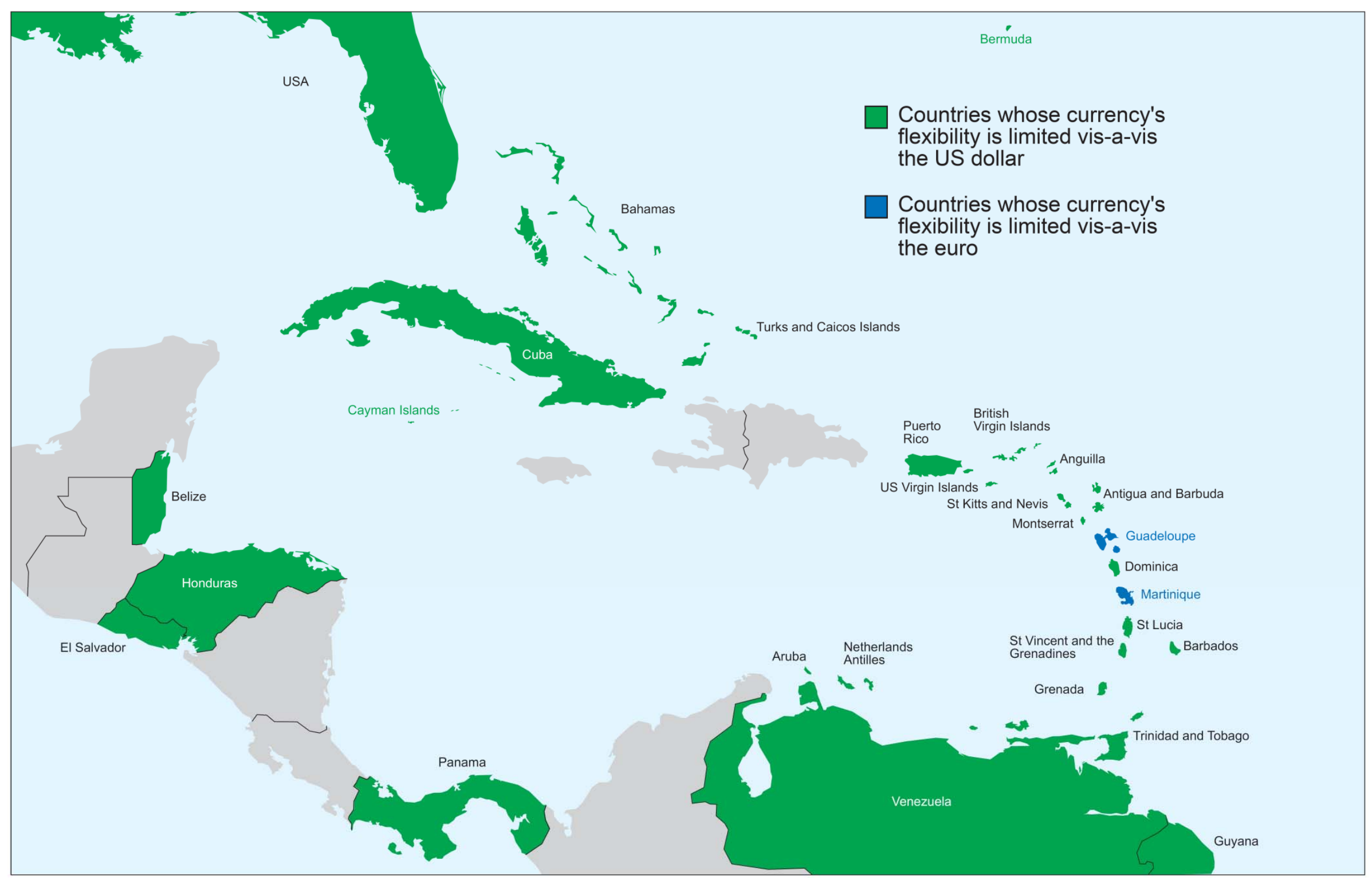


Figure 4: Decision tree on currency regime and anchor currency choice

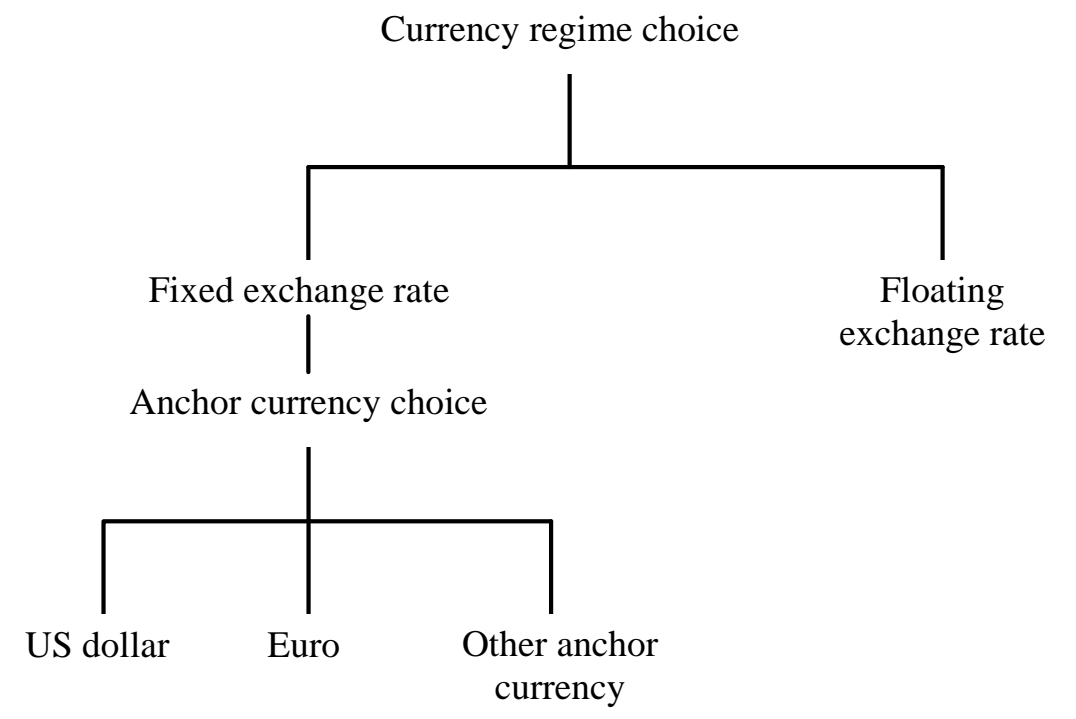


Figure 5: Probabilities of choosing regime options as estimated for 2008

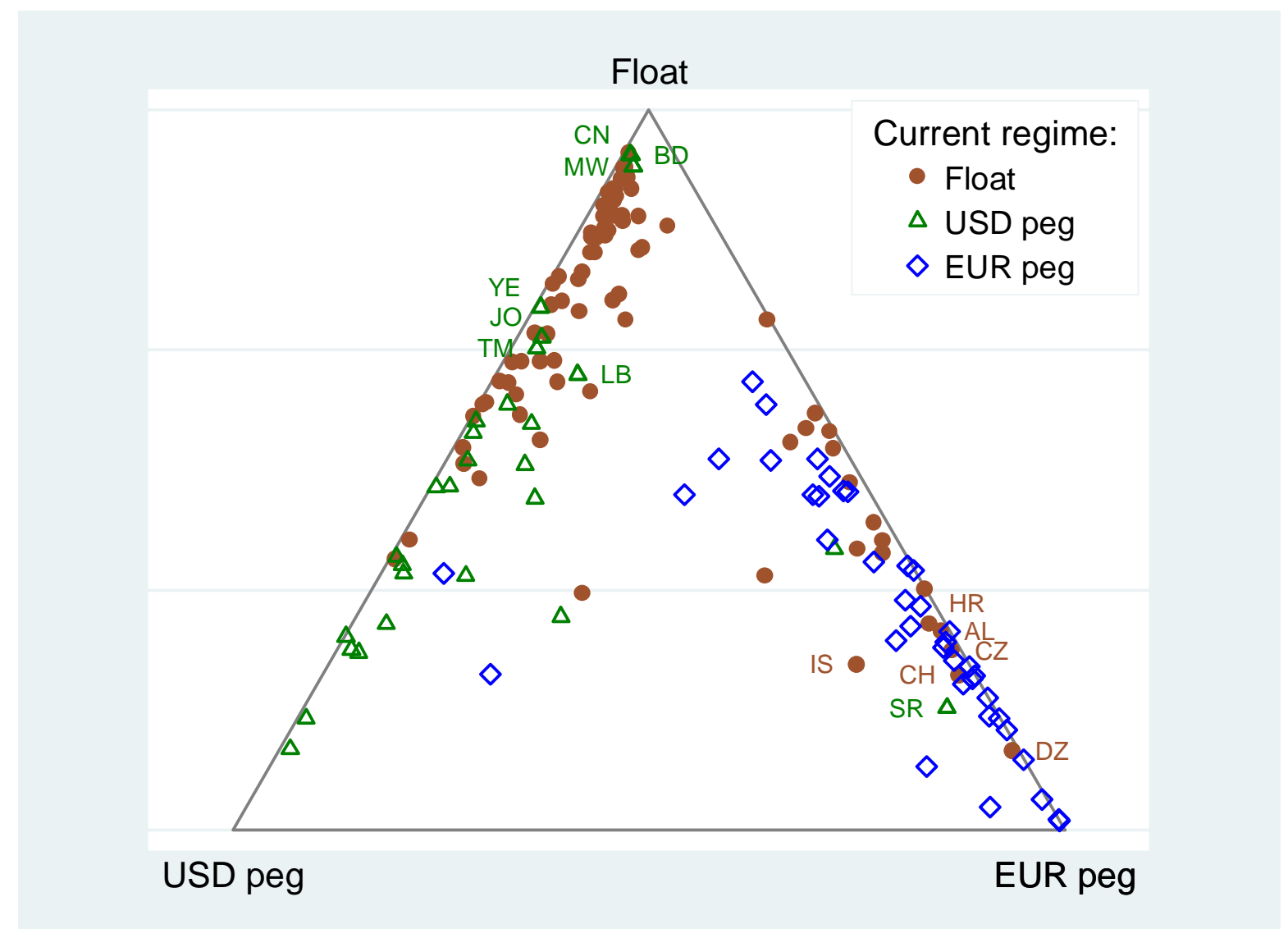

Note: Country ISO codes are tabulated in Appendix 1. 
Figure 6: Probabilities of choosing regime options as estimated using pooled data for 1999 - 2008; most recent observation available

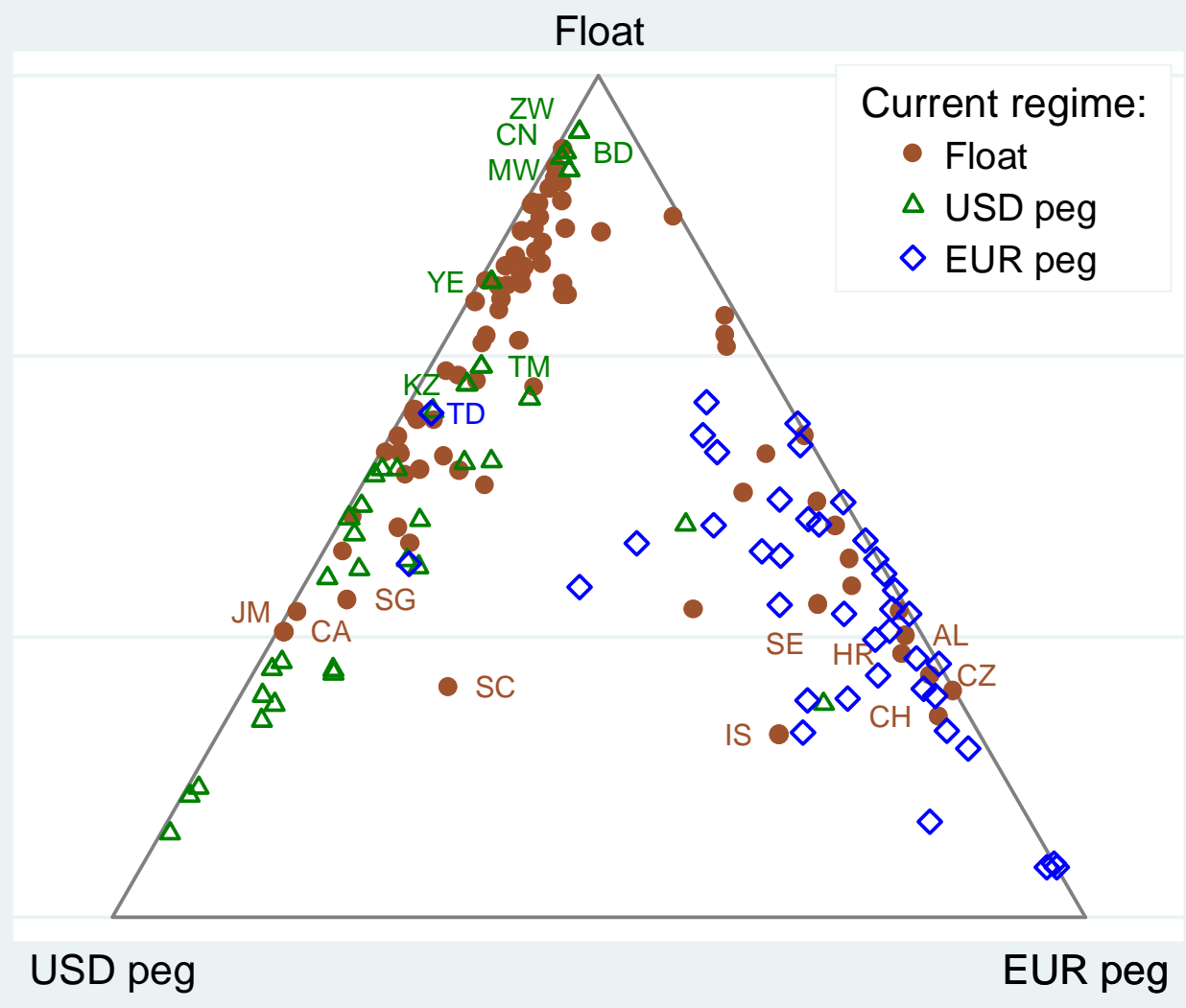

Note: Country ISO codes are tabulated in Appendix 1. 